\title{
氟离子苂光探针设计、合成与应用的新进展
}

\author{
张惠敏吴彦城* 尤嘉宜 曹 梁 \\ 丁 沙蒋凯汪朝阳* \\ (华南师范大学化学与环境学院 教育部环境理论化学重点实验室 广州 510006)
}

\begin{abstract}
摘要 近年来, 生物体内外微量氟离子的识别与检测, 受到了越来越多的关注. 其中，由于苂光检测技术具有灵敏性 高、选择性好、操作方便等优点，不断有各种新颖的氟离子荧光探针被设计与合成. 根据荧光探针的结构特点和识别 机制，将氟离子苂光探针分为去质子化型和反应型两大类，从绿色化学的观点出发，重点综述了近三年来国内外氟离 子苂光探针在分子设计、合成与应用的新进展，并展望了氟离子荧光探针的发展方向.
\end{abstract}

关键词 氟离子; 苂光探针; 分子设计; 合成; 绿色化学

\section{New Progress in the Design, Synthesis and Application of Fluorescent Probes for Fluoride Ion Detection}

\author{
Zhang, Huimin Wu, Yancheng* You, Jiayi Cao, Liang \\ Ding, Sha Jiang, Kai Wang, Zhaoyang* \\ (Key Laboratory of Theoretical Chemistry of Environment, Ministry of Education, School of Chemistry and Environment, \\ South China Normal University, Guangzhou 510006)
}

\begin{abstract}
The recognition and detection of trace fluoride ions in vivo and vitro have attracted great attention in recent years. More and more new fluorescent probes (FP) for fluoride ion detection have been designed and synthesized due to their advantages, such as high sensitivity, good selectivity and convenient operation. According to the different structural features and recognition mechanism, fluoride ion FP can be classified into two categories as deprotonation and reaction type. The new progress especially in recent three years on their molecular design, synthesis and application is reviewed on the viewpoint of green chemistry. The future trend of fluoride ion FP is also prospected.

Keywords fluoride ion; fluorescent probe; molecular design; synthesis; green chemistry
\end{abstract}

氟是人体内不可缺少的微量元素, 但只要氟在人体 内超出一定的浓度, 就会对人体产生严重的危害. 随着 氟离子在工业上的广泛应用, 其对环境造成的不可逆转 的污染和伤害也日益明显. 因此, 生物体内外微量氟离 子的识别与检测, 受到了越来越多的关注 ${ }^{[1 \sim 9]}$. 其中, 由于荧光检测技术具有灵敏性高、选择性好、操作方便 等优点, 使得新型氟离子荧光探针的设计与开发, 一直 成为化学家们的研究重点 ${ }^{[6 ~ 11]}$. 前期已有相关综述从不 同的侧面总结了氟离子荧光探针的研究情况 ${ }^{[6 \sim 11]}$, 但近 年来(特别是最近三年)新的进展不断涌现, 而且侧重于
绿色化学的分子设计与合成, 应用的综述较少. 鉴于此, 本文对氟离子苂光探针设计、合成与应用的最新进展进 行了综述.

\section{1 去质子化型的氟离子荧光探针}

氟原子的电负性较大，容易与强极性的 $\mathrm{OH}$ 或 $\mathrm{NH}$ 结合而形成氢键. 因此, 氟离子可使含有 $\mathrm{NH}$ 或 $\mathrm{OH}$ 的 荧光探针分子产生去质子化作用, 导致其光学性质发生 改变, 从而实现对氟离子的检测.

\footnotetext{
*E-mail: wangzy@scnu.edu.cn,wuycity@gmail.com

Received June 6, 2016; revised June 28, 2016; published online July 15, 2016

Project supported by the Natural Science Foundation of Guangdong Province (No. 2014A030313429) and the 3rd Talents Special Funds of Guangdong Higher Education (No. Guangdong-Finance-Education [2011]431), Guangzhou Science and Technology Project Scientific Special (No. 201607010251).

广东省自然科学基金(No. 2014A030313429)、广东省高等学校人才引进专项资金(粤财教[2011]431 号), 广州市科技计划科学研究专项(No. 201607010251)资助项目.
} 


\section{$1.1 \mathrm{NH}$ 类的去质子化}

胺类等化合物中的 $\mathrm{NH}$ 基团能与氟离子发生配位作 用 ${ }^{[12]}$, 并能进一步发生去质子化 ${ }^{[13]}$, 故可被广泛地用作 氟离子的识别基团. 按照作用位点的多少, 此类氟离子 探针可分为单位点型和多位点型(其含有 2 个或 2 个以 上的去质子化作用位点).

\subsection{1 单位点型的去质子化}

Sarkar 等 ${ }^{[14]}$ 以丹磺酰氯、1,3-丙二胺和 4-氯-7-硝基 苯并噁二唑(1)为原料, 合成了同时含有丹磺酰胺和硝 基苯并噁二唑(NBD)这两种苂光团的化学传感器 2 (Scheme 1). 在 $\mathrm{CH}_{3} \mathrm{CN}$ 溶液中, 加入 $\mathrm{F}^{-}$, 原 $527 \mathrm{~nm}$ 处的 荧光发射峰减弱, 这是因为 $\mathrm{F}^{-}$与传感器 2 中连接在 $\mathrm{NBD}$ 基团上的 $\mathrm{NH}$ 以氢键形式结合，进而发生去质子化 作用, 加强了其光诱导电子转移过程(PET), 从而导致 苂光猝灭. $\mathrm{F}^{-}$与传感器 $\mathbf{2}$ 的络合常数可达 $1.15 \times 10^{5}$ $\mathrm{L} \cdot \mathrm{mol}^{-1}$, 故传感器 $\mathbf{2}$ 可实现对 $\mathrm{F}^{-}$的检测. 此外, 该传感 器还可用于活细胞中 $\mathrm{F}^{-}$检测.

也可通过取代、酯化、共聚等系列反应, 将荧光团 NBD 嵌入到高分子中, 从而制备出荧光探针 3 (Scheme 2). 向该 “turn-off” 型苂光探针 $\mathbf{3}$ 的 THF 溶液中加入
$\mathrm{F}^{-}$, 其 $515 \mathrm{~nm}$ 处荧光发射峰发生猝灭, 紫外最大吸收 峰从 $450 \mathrm{~nm}$ 红移到 $460 \mathrm{~nm}$, 且在 395 和 $409 \mathrm{~nm}$ 处产生 新的吸收峰, 由裸眼可见溶液颜色从绿色变为淡黄色. 这是因为 $\mathrm{F}^{-}$与探针 3 的 $\mathrm{NH}$ 形成氢键, 继而发生去质子 化作用(Scheme 2). 其他离子几乎无影响，因此该探针 可实现对 $\mathrm{F}^{-}$的高选择性检测, 其检测限约为 $8 \times 10^{-7}$ $\mathrm{mol} / \mathrm{L}^{[15]}$.

苯并硒二唑类化合物具有较强苂光效应、较大摩尔 吸光系数和较强耐光性的性质. 类似地, 也可以其为原 料, 以三(二亚苄基丙酮)二钯 $\left[\mathrm{Pd}_{2}(\mathrm{dba})_{3}\right]$ 为催化剂, 以 $1,1^{\prime}$-双二苯基膦二茂铁(dppf)为配体，通过溴代芳烃的 胺化反应来制备同时含有硝基和 $\mathrm{NH}$ 的 $\mathrm{F}^{-}$苂光探针 $\mathbf{4}$ (Eq. 1). 向 4 的二甲基亚砜(DMSO)溶液中加入 $\mathrm{F}^{-}$之后, 原 $402 \mathrm{~nm}$ 处紫外吸收峰消失, 而 $498 \mathrm{~nm}$ 和近红外的 $691 \mathrm{~nm}$ 处产生了新的吸收峰, 可明显观察到溶液由红 色变为深蓝色. 荧光滴定实验中, 随着 $\mathrm{F}^{-}$浓度增加, 探 针 4 原本在 $671 \mathrm{~nm}$ 处的发射峰逐渐猝灭, 而 $478 \mathrm{~nm}$ 处 产生了一个新的荧光发射峰并显著增强. 这些变化的原 因，是 $\mathrm{F}^{-}$的加入导致 $\mathrm{NH}$ 发生去质子化作用，从而抑制 了激发态分子内质子转移过程(ESIPT), 导致光谱改变.<smiles>CN(C)c1cccc2c(S(=O)(=O)Cl)cccc12</smiles><smiles>CCOCCOCCN</smiles>
$88 \%$<smiles>CN(C)c1cccc2c(S(=O)(=O)NCCCN)cccc12</smiles>
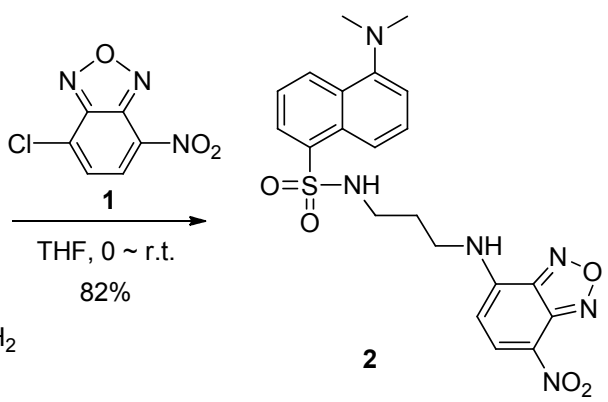

图式 1 传感器 2 的合成

Scheme 1 Synthesis of sensor 2<smiles>O=[N+]([O-])c1ccc(Cl)c2nonc12</smiles>

(1) Substitution reaction with ethanolamine

(2) Esterification with acrylic acid

(3) Copolymerization with styrene<smiles>CCCC(CC(C)C)c1ccccc1</smiles><smiles>CC(C)CC(CC(C)C)C(=O)OCC[N-]c1ccc([N+](=O)[O-])c2nonc12</smiles>

图式 2 探针 3 的合成及其作用机理

Scheme 2 Synthesis of probe $\mathbf{3}$ and its mechanism<smiles>SCc1csc(-c2ccc(Br)c3n[se]nc23)c1</smiles>

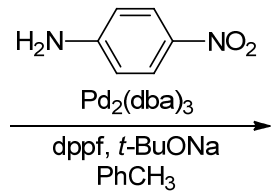

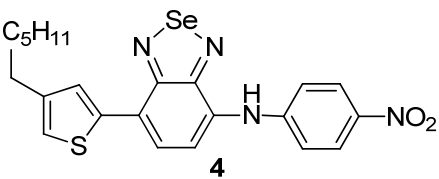

4 
在其他离子的实验中, 光谱没有发生变化, 故该探针对 $\mathrm{F}^{-}$有高选择性和灵敏性 ${ }^{[16]}$.

罗丹明是常见的荧光团, 可用于设计选择性检测氟 离子的苂光探针. 例如, Chellappa 等 ${ }^{[17]}$ 将咪唑分子通过 $\mathrm{C}=\mathrm{N}$ 键引进到罗丹明 $6 \mathrm{G}$ 中, 设计出了 “turn-on” 型苂 光探针 5 (Scheme 3). 在 4-羟乙基哌嗪乙硫磺酸 (HEPES) 缓冲液(含 $30 \% \mathrm{CH}_{3} \mathrm{CN}$ )中, 5 原本没有明显的 紫外吸收峰, 加入 $F^{-}$之后, 在 $528 \mathrm{~nm}$ 处出现吸收峰, 且 裸眼可见溶液颜色由无色变为粉色; 且随着 $\mathrm{F}^{-}$浓度增 加, $557 \mathrm{~nm}$ 处产生一个新的苂光发射峰, 其荧光强度逐 渐增强. 这是因为在 $\mathrm{F}^{-}$的诱导下, 咪唑中的 $\mathrm{NH}$ 与 $\mathrm{F}^{-}$形 成氢键, 继而使其脱质子化, 诱导探针 $\mathbf{5}$ 发生开环反应, 从而引起苂光强度的变化. 相比之下其他离子没有引起 明显变化, 故该探针可实现对 $\mathrm{F}^{-}$的高选择性和高灵敏 性检测. 探针 5 和 $\mathrm{F}^{-}$的络合常数为 $2.13 \times 10^{3} \mathrm{~L} / \mathrm{mol}$, 对 $\mathrm{F}^{-}$检测限可达 $8.52 \times 10^{-9} \mathrm{~mol} / \mathrm{L}$. 此外, 其还可应用于 宫颈癌细胞等活细胞中 $\mathrm{F}^{-}$的苂光成像.

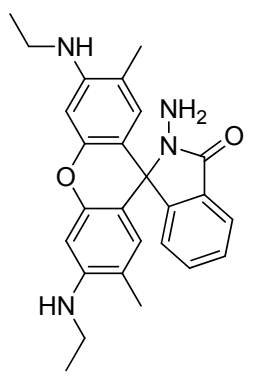

(F)

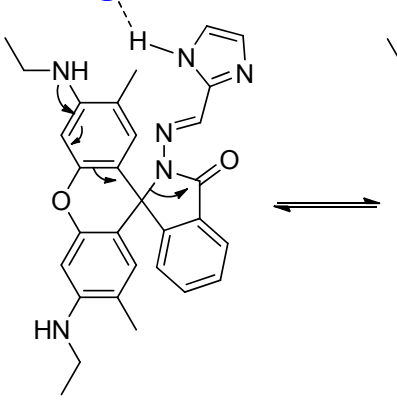

图式 3 探针 5 的合成及其作用机理

Scheme 3 Synthesis of probe 5 and its mechanism

类似地, 苯并咪唑环上的 $\mathrm{NH}$ 也可发生去质子化作 用而检测氟离子 ${ }^{[18]}$. 例如, Raposo 等 ${ }^{[19]}$ 合成了苯并咪唑 化合物 6 (Eq. 2). 向化学传感器 6 的 $\mathrm{CH}_{3} \mathrm{CN}$ 溶液中加入 $\mathrm{F}^{-}$, 紫外吸收峰从 $422 \mathrm{~nm}$ 红移到 $493 \mathrm{~nm}$; 苂光发射峰 从 $624 \mathrm{~nm}$ 红移至 $650 \mathrm{~nm}$ 处, 并且荧光强度显著增强, 溶液颜色由黄色变为粉色. 这是因为 $\mathrm{F}^{-}$的加入引起去 质子化作用, 导致光谱发生改变, 故传感器 6 可实现对 $\mathrm{F}^{-}$的检测.

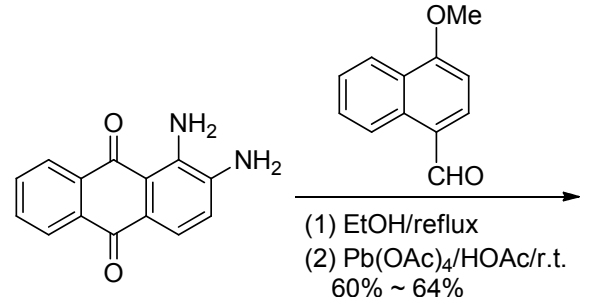<smiles>COc1ccc(-c2nc3ccc4c(c3[nH]2)C(=O)c2ccccc2C4=O)c2ccccc12</smiles>

最近, Misra 等 ${ }^{[20]}$ 通过多聚磷酸(PPA)催化的缩合等 反应，合成了咪唑衍生物 7 (Scheme 4). 向探针 7 的 DMSO 水溶液中加入 $\mathrm{F}^{-}$, 其 $370 \mathrm{~nm}$ 处的紫外吸收峰消 失, $455 \mathrm{~nm}$ 处产生新的吸收峰, 且裸眼可见溶液颜色由 橙红色变为无色; 其 $488 \mathrm{~nm}$ 处的荧光发射峰猝灭, 455 和 $586 \mathrm{~nm}$ 处产生新的发射峰. 这是因为 $\mathrm{F}^{-}$能与探针的 $\mathrm{NH}$ 形成氢键，继而导致其发生去质子化，增强了从咪 唑环到苯并噻唑环的分子内电荷转移(ICT)过程, 使得 光谱发生改变, 从而实现对 $\mathrm{F}^{-}$的检测.<smiles>O=Cc1ccc(C(=O)O)cc1</smiles>

(1) $\mathrm{NH}_{4} \mathrm{OAc}, \mathrm{HOAC}$<smiles>Nc1ccccc1S</smiles><smiles>c1ccc(-c2nc(-c3ccc(-c4nc5ccccc5s4)cc3)[nH]c2-c2ccccc2)cc1</smiles>

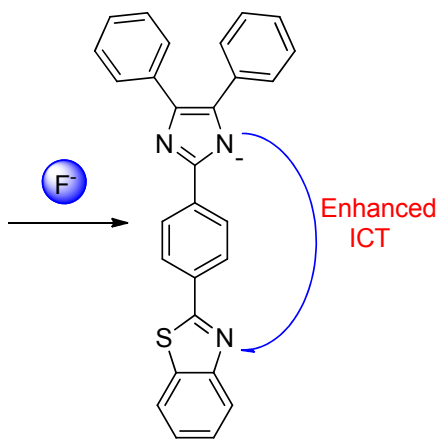

图式 4 探针 7 的合成及其作用机理

Scheme 4 Synthesis of probe 7 and its mechanism

在国内, 最近 $\mathrm{Liu}$ 等 ${ }^{[21]}$ 以 2,3 -二氨基吩嗪和对溴苯 甲醛为原料, 合成基于咪唑和吩嗪的 $\mathrm{F}^{-}$探针 8 (Eq. 3). 在探针的 DMSO 溶液中加入 5 equiv.的 $\mathrm{F}^{-}$后, 紫外吸收 峰由 $405 \mathrm{~nm}$ 红移到 $435 \mathrm{~nm}$, 同时在 $550 \mathrm{~nm}$ 附近出现一 个宽的吸收带，日光灯下观察到溶液由黄色变成了红 色. 苂光滴定实验中，随着 $\mathrm{F}^{-}$浓度增加, $530 \mathrm{~nm}$ 处的苂 光发射峰逐渐猝灭, 当加入的 $\mathrm{F}^{-}$量达 11 equiv. 时该峰完 
全消失, 而在 $650 \mathrm{~nm}$ 处产生一个新的苂光峰, 菼光颜色 由绿变红. 其他离子没有引起明显变化, 这是因为咪唑 基团的 $\mathrm{N}-\mathrm{H}$ 先与 $\mathrm{F}^{-}$形成氢键, 再发生去质子化作用, 使 得探针光谱改变. 探针 $\mathbf{8}$ 对 $\mathrm{F}^{-}$的检测限可达 $6.2 \times 10^{-6}$ $\mathrm{mol} / \mathrm{L}$. 不仅如此, 该探针还能实现水溶液环境中 $\mathrm{F}^{-}$的 检测，故有望应用于生理学和环境领域.<smiles>Nc1cc2nc3ccccc3nc2cc1N</smiles><smiles>O=Cc1ccc(Br)cc1</smiles><smiles>Brc1ccc(-c2nc3cc4nc5ccccc5nc4cc3[nH]2)cc1</smiles>

苯腙类化合物中的 $\mathrm{NH}$, 也可发生去质子化而应用 为检测氟离子的传感器, 如化合物 9 (Eq. 4) ${ }^{[22]}$. 金属络 合物类检测氟离子也有文献报道 ${ }^{[23]}$, 特别是一些金属 离子与含有质子的有机物配位后, 络合物可与 $\mathrm{F}^{-}$发生 作用而导致荧光改变, 从而检测 $\mathrm{F}^{-[24 ~ 26]}$.<smiles>O=CC1=CSC(=C2SC=CS2)S1</smiles><smiles>NNc1ccc([N+](=O)[O-])cc1[N+](=O)[O-]</smiles><smiles>O=[N+]([O-])c1ccc(N/N=C/C2=CSC(=C3SC=CS3)S2)c([N+](=O)[O-])c1</smiles>

例如, 最近 Elango 等 ${ }^{[27]}$ 先以 2,3-二氯-1,4-菜醌和 $N, N$-二甲基乙二胺为原料合成化合物 $\mathbf{1 0}$, 其再与金属 $\mathrm{Zn}$ 螯合，可得基于金属配合物的探针 11 (Scheme 5). 由 于络合后 $\mathrm{NH}$ 的酸性大大增强, 探针 11 与 $\mathrm{F}^{-}$的络合常 数比没有络合金属的化合物 $\mathbf{1 0}$ 高, 使其对 $\mathrm{F}^{-}$的检测能 力大大增强, 故探针 11 可实现对 $\mathrm{F}^{-}$的高选择性检测, 其检测限可达 $5 \times 10^{-8} \mathrm{~mol} / \mathrm{L}$.<smiles>CCOCCN(C)CCN</smiles>

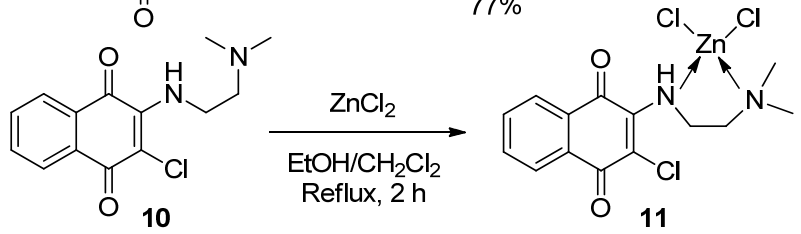

图式 5 探针 11 的合成 Scheme 5 Synthesis of probe 11

\subsection{2 多位点型的去质子化}

含有二个酰胺键 ${ }^{[28]}$ 的化合物可去质子化而检测氟 离子. 类似地, 芳香环腙 $\mathrm{N}-\mathrm{H}$ 键 ${ }^{[29,30]}$ 也可使腙类化合 物成为氟离子传感器. 例如, 崔玉等 ${ }^{[31}$ 通过 2 -吡啶肼与 芳香醛的缩合反应，合成基于吡咯并吡咯二酮的 $\mathrm{F}^{-}$传 感器 12 (Eq. 5). 向 12 的 DMSO 溶液中加入 $F^{-}$, 其紫外 吸收峰发生了很大程度的红移，从 $504 \mathrm{~nm}$ 红移到 771 $\mathrm{nm}$ 的近红外区. 苂光发射光谱也变化较大, $598 \mathrm{~nm}$ 处发 生苂光猝灭. 肉眼可见溶液颜色由红色变为深绿色, 而 在紫外灯下, 苂光颜色由红色变为无荧光. 这是因为腙 $\mathrm{NH}$ 在 $\mathrm{F}^{-}$存在下发生去质子化作用, 引起了光谱的改变. 因此, 传感器 12 可实现对 $\mathrm{F}^{-}$的检测, 其与 $\mathrm{F}^{-}$的络合 常数为 $3.06 \times 10^{7} \mathrm{~L}^{2} \cdot \mathrm{mol}^{-2}$, 检测限达 $2.8 \times 10^{-7} \mathrm{~mol} / \mathrm{L}$.

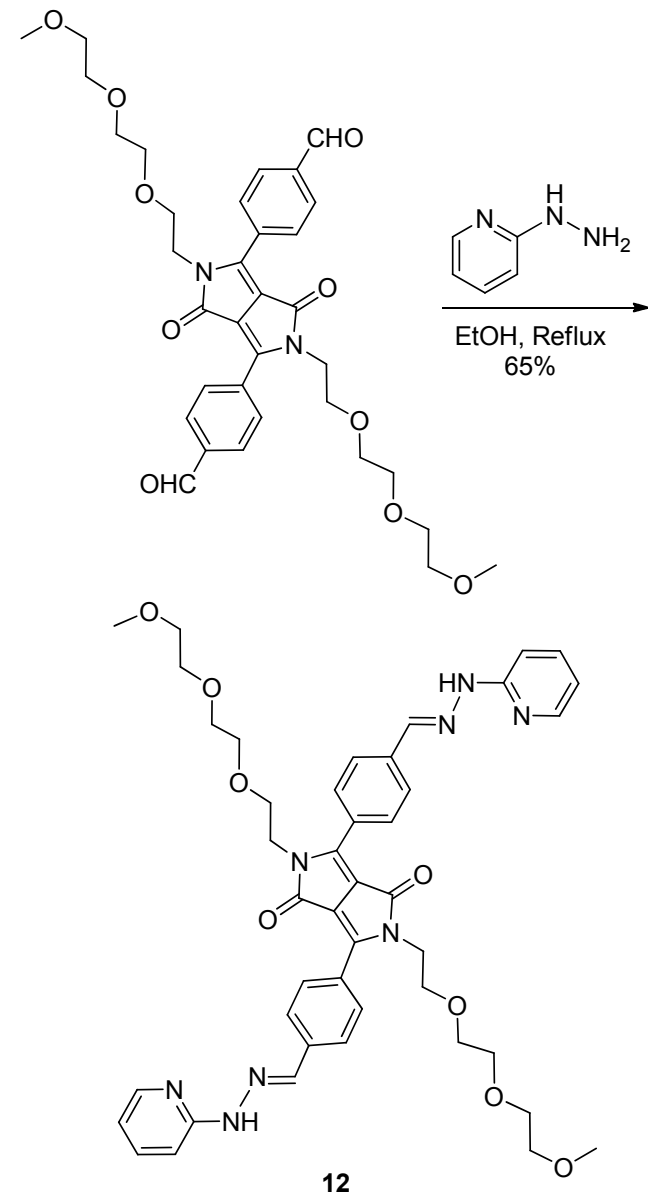

但更常见的，是杂环化合物上的多个 NH 发生去质 子化作用而被用于 $\mathrm{F}^{-}$探针设计 ${ }^{[32]}$. 例如, Iyer 等 ${ }^{[33]}$ 通过 间苯二甲酸与邻苯二胺类化合物的缩合反应，构建了含 有二个苯并咪唑结构的 $\mathrm{F}^{-}$检测传感器 13 (Eq. 6). 在 13 的 $\mathrm{CH}_{3} \mathrm{CN}$ 溶液中, 加入 $\mathrm{F}^{-}$后, 氢键的形成导致 13 原在 $339 \mathrm{~nm}$ 处的紫外吸收峰减弱, 且在 $368 \mathrm{~nm}$ 处有一个等 消光点; 13 原来 $393 \mathrm{~nm}$ 处的苂光发射峰猝灭. 由于其他 阴离子对 13 紫外和苂光的影响程度都远不及 $\mathrm{F}^{-}$, 故 13 
能够实现 $\mathrm{F}^{-}$的选择性检测.

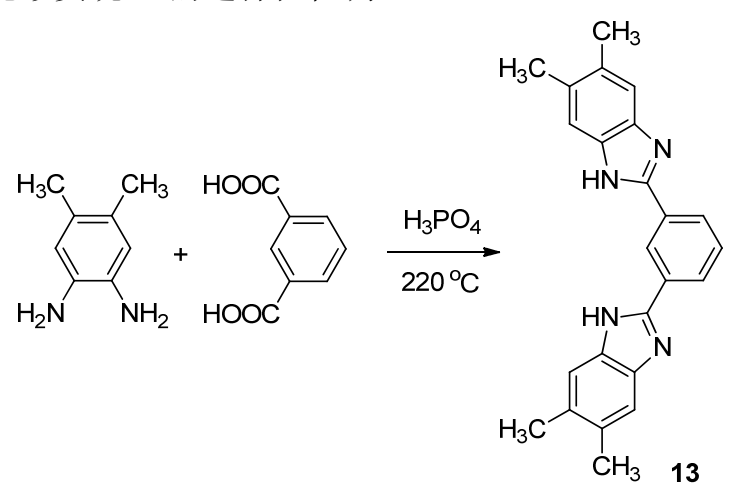

(6)

吲哚类化合物广泛存在于自然界, 近年来基于多吲 哚基化合物发生去质子化而应用为检测氟离子传感器 的报道较多. 例如, 常泽等 ${ }^{[34]}$ 以含有双吲哚基结构的化 合物为原料, 合成了传感器 14 (Eq. 7). 在传感器 $\mathbf{1 4}$ 的 $\mathrm{DMSO} / \mathrm{H}_{2} \mathrm{O}$ 溶液 $(V: V=95: 5)$ 中加入 $\mathrm{F}^{-}, 505 \mathrm{~nm}$ 和 $403 \mathrm{~nm}$ 处的紫外吸收峰增强, $350 \mathrm{~nm}$ 处的吸收峰明显减 弱; $590 \mathrm{~nm}$ 处的苂光发射峰发生猝灭, 且裸眼可见溶液 颜色由黄色变为橙色. 这是因为 $\mathrm{F}^{-}$与传感器以 $2: 1$ 通 过氢键结合, 进一步使其发生去质子化作用, 从而引起 光谱变化. 其他离子对光谱的影响非常微弱, 故该传感 器可以实现对 $\mathrm{F}^{-}$的检测.

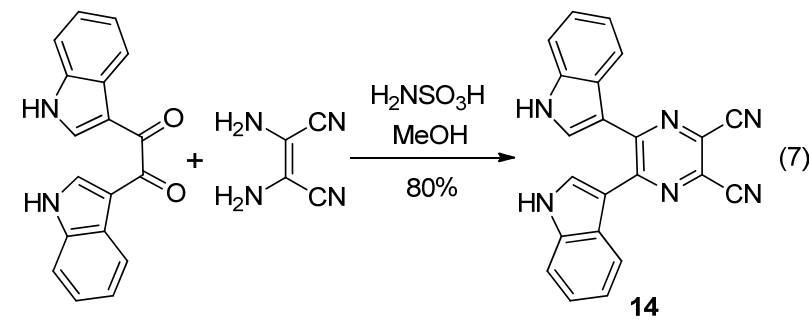

在国外, Chellappa 等 ${ }^{[35]}$ 以吲哚-3-甲醛为原料, 也与 二氨基顺丁烯二腈反应，合成了基于吲哚环的“turn-on” 型 $\mathrm{F}^{-}$传感器 15 (Eq. 8). 不仅如此, 最近他们还在 2-氨基 苯甲酰肼上引入蒽荧光团, 合成双 $\mathrm{NH}$ 作用位点的氟离 子化学传感器 16 (Eq. 9) ${ }^{[36]}$.<smiles>N#C/C(N)=C(/C#N)C(=O)O</smiles>

当然, 多位点型去质子化氟离子苂光探针中最为常 见的化合物是硫脲类 ${ }^{[37]}$. 例如, Velmathi 等 ${ }^{[38]}$ 以硫氰酸 钾、苯甲酰氯和 4-氨基偶氮苯为原料, 经两步反应、“一 锅法” 以 $86 \%$ 的产率合成了化学传感器 17 (Eq. 10). 向 17 的 $\mathrm{CH}_{3} \mathrm{CN}$ 溶液中加入 $\mathrm{F}^{-}, 283 \mathrm{~nm}$ 处的紫外吸收峰减<smiles>NNC(=O)c1ccccc1NNC(=O)c1ccccc1N/N=C/c1c2ccccc2cc2ccccc12</smiles>
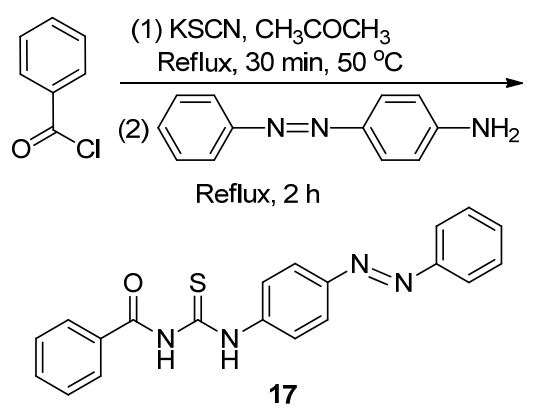

弱, 而 $350 \mathrm{~nm}$ 处的吸收峰增强, 发生了红移. $416 \mathrm{~nm}$ 苂 光发射峰处发生菼光猝灭. 裸眼可见溶液颜色浅黄色变 为亮黄色. 这是因为 $\mathrm{F}^{-}$与 17 以 $1: 1$ 络合形成氢键, 继 而产生了去质子化作用，其激活了 PET 过程而导致光谱 发生改变. 该传感器对 $\mathrm{F}^{-}$的检测限为 $5.36 \times 10^{-7} \mathrm{~mol} / \mathrm{L}$, 其还可应用于牙膏和漱口水等中的 $\mathrm{F}^{-}$检测.

类似地，基于双氨基化合物以 $62 \%$ 总产率生成的双 硫脲化合物 18 (Eq. 11), 也能以多位点作用的方式检测 氟离子[39].

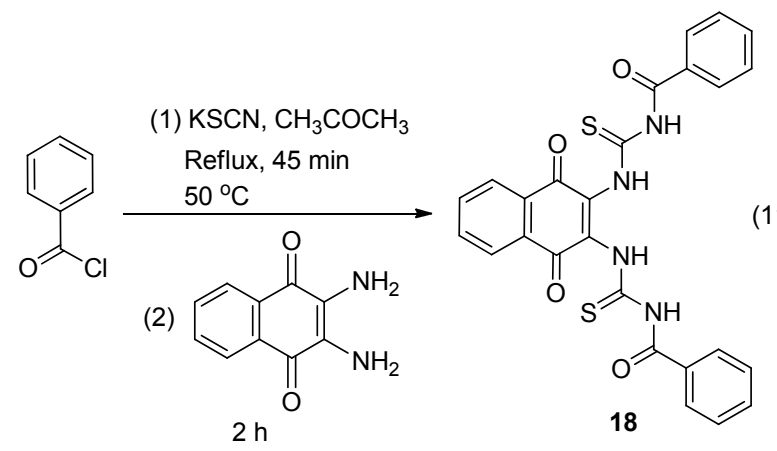

不仅如此，一些类似硫脲的肼类化合物，也是常见 的多位点氟离子检测探针 ${ }^{[40]}$. 例如, Rurack 等 ${ }^{[41]}$ 先将氟 硼二吡咯类苂光分子与肼反应，再与含有吸电子基的对 硝基异硫氧酸苯酯反应，设计合成了 $\mathrm{F}^{-}$苂光探针 19 (Scheme 6). 在 19 的 $\mathrm{DMSO} / \mathrm{H}_{2} \mathrm{O}(V: V=1: 1)$ 溶液中加 入 $\mathrm{F}^{-}, 513 \mathrm{~nm}$ 处的苂光发射峰发生猝灭, 这是因为 $\mathrm{F}^{-}$ 先与硫嫝基团上的 $a 、 b$ 两个位点的 NH 结合形成氢键, 接着 $\mathrm{b}$ 位点的 $\mathrm{NH}$ 进一步脱质子化. 加入 $\mathrm{CH}_{3} \mathrm{COO}^{-}$和 $\mathrm{H}_{2} \mathrm{PO}_{4}{ }^{-}$虽然对探针 19 有类似的影响, 但是其影响程度 远不及 $\mathrm{F}^{-}$, 故探针 19 可实现了对 $\mathrm{F}^{-}$的检测, $\mathrm{F}^{-}$与探针 19 的络合常数为 $5.34 \times 10^{4} \mathrm{~L} / \mathrm{mol}$, 检测限为 $2.4 \times 10^{-7}$ 
$\mathrm{mol} / \mathrm{L}$.
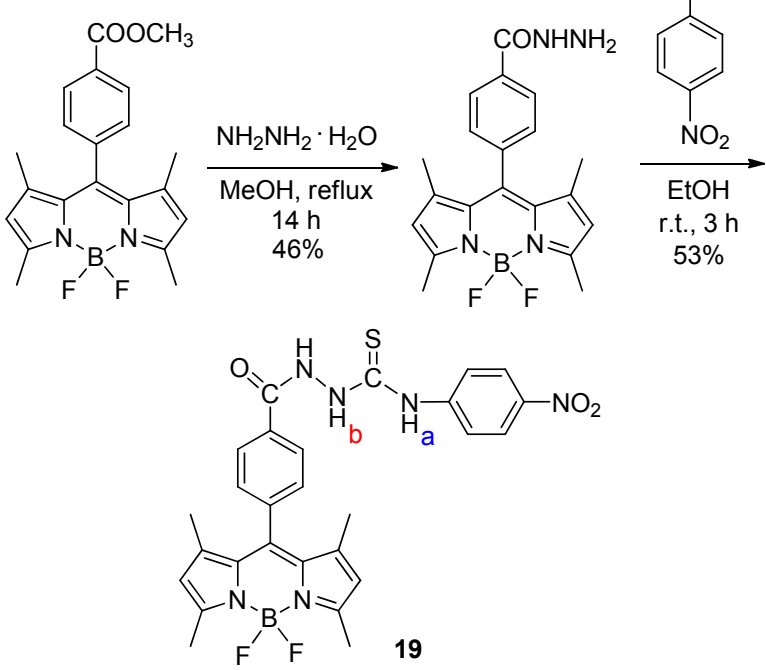

图式 6 探针 19 的合成

Scheme 6 Synthesis of probe 19

最近袁耀锋等 ${ }^{[42]}$ 以 $\beta$-䒺酚为原料, 经过多步反应合 成了苯并香豆素硫嫝类的 $\mathrm{F}^{-}$探针 $\mathbf{2 0}$ (Scheme 7). 在 $\mathbf{2 0}$ 的 DMSO 溶液中, 随着 $\mathrm{F}^{-}$的加入, 在 $385 \mathrm{~nm}$ 处的吸收 峰逐渐减弱, 在 $400 \sim 500 \mathrm{~nm}$ 区域出现三个新的吸收峰, 裸眼可见溶液颜色由无色变为黄色; 同时, 荧光强度明 显增强. 这是因为加入的 $\mathrm{F}^{-}$先与受体分子上活泼氢通 过氢键作用相结合, 一分子 $\mathrm{F}^{-}$和硫艮上两个 $\mathrm{NH}$ 以氢键 形式构成六元环, 另外一分子 $\mathrm{F}^{-}$与酰胺上 $\mathrm{NH}$ 氢键作 用, 受体分子与 $\mathrm{F}^{-}$形成 $1: 2$ 的配合物, 进一步作用导
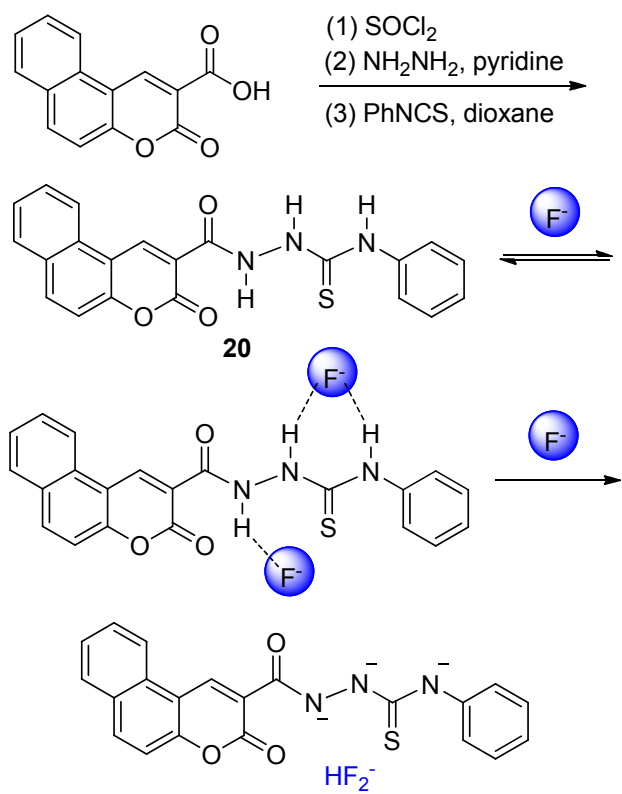

图式 7 探针 $\mathbf{2 0}$ 的合成及其作用机理

Scheme 7 Synthesis of probe $\mathbf{2 0}$ and its mechanism
致 20 发生去质子化后开启了 ICT 过程而引起光谱改变. 探针 20 检测限为 $2.5 \times 10^{-8} \mathrm{~mol} / \mathrm{L}$, 响应时间为 $5 \mathrm{~min}$.

肼硫艮类多位点氟离子传感器的获得, 除上述利用 酰肼类化合物与异硫氧酸苯酯反应外，也可先将肼结构 引入硫艮, 进而与芳香醛缩合, 从而制备出含有 $\mathrm{C}=\mathrm{N}$ 键的肼硫脲类多位点氟离子传感器, 如最近 Sreekanth 等 ${ }^{[43]}$ 合成的传感器 $\mathbf{2 1}$ (Scheme 8).

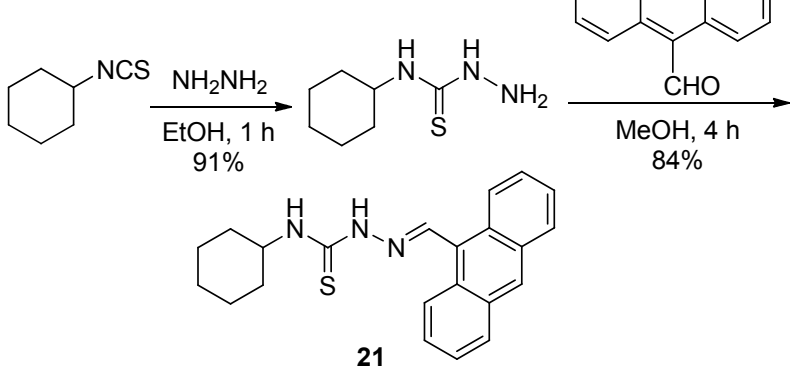

图式 8 传感器 21 的合成

Scheme 8 Synthesis of sensor 21

Hundal 等 ${ }^{[44]}$ 以芳香醛 22 与化合物 $\mathbf{2 3}$ 缩合, 合成了 传感器 24 (Scheme 9). 在 $\mathbf{2 3}$ 的 DMSO 溶液中加入 $F^{-}$, $337 \mathrm{~nm}$ 处的紫外吸收峰消失, $402 \mathrm{~nm}$ 处产生新的吸收 峰, 红移了 $65 \mathrm{~nm}$, 且裸眼可见溶液颜色由无色变为浅 黄绿色; 传感器 24 原本没有明显的荧光发射峰, 加入 $\mathrm{F}^{-}$之后，在 $438 \mathrm{~nm}$ 产生一个最大荧光发射峰，并且在 375 和 $480 \mathrm{~nm}$ 处产生了两个肩峰. 这是因为 $\mathrm{F}^{-}$和两个 缩氨基硫脲基团上的四个 $\mathrm{N}-\mathrm{H}$ 络合形成氢键，继而使其 发生去质子化作用, 减弱了 PET 过程从而导致光谱发生 改变，而其他离子几乎没有影响. 因此，传感器 $\mathbf{2 4}$ 可实 现对 $\mathrm{F}^{-}$的高选择性检测, 其与 $\mathrm{F}^{-}$的络合常数为 $2.66 \times$ $10^{3} \mathrm{~L} / \mathrm{mol}$, 检测限约为 $2 \times 10^{-5} \mathrm{~mol} / \mathrm{L}$.
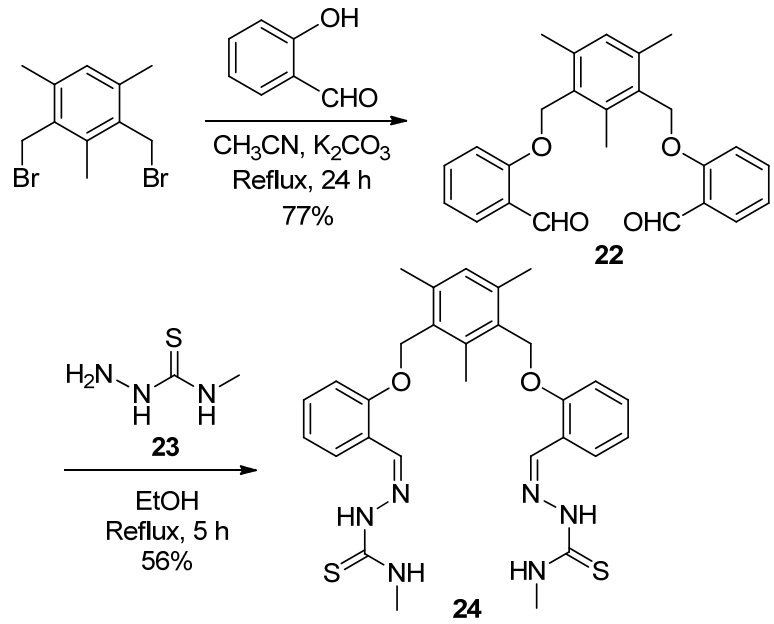

图式 9 传感器 24 的合成

Scheme 9 Synthesis of sensor 24 
最近，杨小风等 ${ }^{[45]}$ 在吡咯并吡咯二酮中引入两个 含有活泼 $\mathrm{NH}$ 的硫嫝基团, 合成了 $\mathrm{F}^{-}$化学传感器 $\mathbf{2 5}$ (Eq. 12). 在 $\mathbf{2 5}$ 的 DMSO 溶液中加入 $\mathrm{F}^{-}$, 紫外吸收峰由 510 $\mathrm{nm}$ 红移到 $588 \mathrm{~nm}$ 处, $525 \mathrm{~nm}$ 处有等吸收点出现; 而 587 $\mathrm{nm}$ 处的荧光发射峰发生猝灭. 日光灯下可见溶液颜色 由橙色变为淡蓝色, 而紫外灯下可见溶液颜色由苂光橙 红色变为非苂光蓝色. 这是因为 $F^{-}$与 25 以 $2: 1$ 通过氢 键作用结合(结合位点为硫脲基团的 $\mathrm{NH}$ ), 进一步引起 去质子化作用导致光谱改变. 25 与 $\mathrm{F}^{-}$的络合常数为 $3.24 \times 10^{7} \mathrm{~L}^{2} \cdot \mathrm{mol}^{-2}$, 检测限为 $4.2 \times 10^{-8} \mathrm{~mol} / \mathrm{L}$.<smiles>CCCN1C(=O)C2=C(c3ccc(C=O)cc3)N([14CH3])C(=O)C2=C1c1ccc(C=O)cc1</smiles><smiles>NC(=S)N/N=C/c1ccc(C2=C(c3ccc(/C=N/NC(N)=S)cc3)C(c3ccccc3)N([C+](=O)[O-])C2=O)cc1</smiles>

其实, 不仅仅是硫䐂类化合物, 其他具有双肼结构 的化合物 (如碳酰肼 26) 也可用于制备多位点氟离子传感 器, 如最近 Mahapatra 等 ${ }^{[46]}$ 合成的化合物 27 (Eq. 13). 向 27 的 DMSO 溶液中加入 $\mathrm{F}^{-}$, 随着 $\mathrm{F}^{-}$的加入量由 0 增加 到 20 equiv., 其紫外吸收光谱原 375 和 $392 \mathrm{~nm}$ 的吸收峰 逐渐减弱, 在 $435 \mathrm{~nm}$ 产生了新的吸收峰; 在 $455 \mathrm{~nm}$ 处 的苂光发射峰发生猝灭, 苂光颜色由蓝色变为浅蓝色, 并且肉眼可观测到溶液颜色由无色变为黄色. 当 $\mathrm{F}^{-}$浓 度进一步增加(超过 20 equiv. 后), 375 和 $392 \mathrm{~nm}$ 的吸收 峰逐渐减弱, 产生蓝移; 而其荧光发射峰红移, $505 \mathrm{~nm}$ 处产生新的发射峰且强度显著增强, 裸眼可见溶液颜色 进一步从黄色变为红褐色. 产生上述变化的原因, 可能
是由于 $\mathrm{F}^{-}$先后与杂环上 $\mathrm{NH}$ 和嫝基 $\mathrm{NH}$ 结合形成氢键, 以 $3: 1$ 的比例与 27 络合, 进一步发生去质子化, 形成 $\mathrm{HF}_{2}{ }^{-}$离子, 导致光谱改变. 其他离子对光谱几乎没有影 响, 故该探针对 $\mathrm{F}^{-}$具有高选择性和灵敏性, 其检测限约 为 $5.2 \times 10^{-6} \mathrm{~mol} / \mathrm{L}$.

利用硫代碳酰肼制备的传感器，其检测效果也较 好. 例如, Singh 等 ${ }^{[47]}$ 以硫代碳酰肼与 7-(二乙胺基)香豆 素-3-甲醛反应，合成了 “On-Off-On” 型 $\mathrm{F}^{-}$化学传感器 28 (Eq. 14), 向其 $\mathrm{CH}_{3} \mathrm{CN}$ (含 $0.25 \%$ DMSO) 溶液中加入 $\mathrm{F}^{-}, 516 \mathrm{~nm}$ 处的苂光发射峰发生猝灭, 当加入的 $\mathrm{F}^{-}$达 7.2 equiv.后, $490 \mathrm{~nm}$ 处开始产生新的发射峰. 之所以产 生以上 “On-Off-On” 的苂光变化, 是因为 $\mathrm{F}^{-}$能通过氢 键，与硫脲基团上的两个 $\mathrm{NH}$ 以 $1: 1$ 结合, 并进一步导 致传感器分子发生去质子化作用, 导致光谱改变. 其他 离子均没有产生类似的现象, 故传感器 $\mathbf{2 8}$ 能实现对 $\mathrm{F}^{-}$ 的选择性检测.

\section{$1.2 \mathrm{OH}$ 类的去质子化}

\subsection{1 纯 $\mathrm{OH}$ 型的去质子化}

许多含有 $\mathrm{OH}$ 的化合物都可作为探针而应用于 $\mathrm{F}^{-}$ 的检测 ${ }^{[48 \sim 51]}$, 其中包括利用去质子化机理的检测 ${ }^{[52 \sim 55]}$. 从合成上看, 利用羟基芳香醛(特别是生物性资源水杨 醛)为原料, 与各种含有 $\mathrm{NH}_{2}$ 的化合物进行缩合反应, 是 这类探针的主要合成方法 ${ }^{[56]}$.

例如, Velmathi 等 ${ }^{[57]}$ 以 4-氨基偶氮苯和 5-氯水杨醛 为原料, 设计合成了含有酚羟基的 $\mathrm{F}^{-}$荧光探针 29 (Eq. $15)$. 在 29 的 $\mathrm{DMSO} / \mathrm{H}_{2} \mathrm{O}(V: V=9: 1)$ 溶液中加入 $\mathrm{F}^{-}$, $375 \mathrm{~nm}$ 处紫外吸收峰减弱, $520 \mathrm{~nm}$ 处增强, 且裸眼可见 溶液由黄色变浅粉色; 而其 $480 \mathrm{~nm}$ 处的苂光发射峰增 强. 产生以上变化的原因, 是 $\mathrm{F}^{-}$与探针的酚 $\mathrm{OH}$ 以氢键 结合, 进一步促进其去质子化, 导致光谱发生改变, 故 29 可实现 $\mathrm{F}^{-}$的检测. 不足的是, 加入 $\mathrm{AcO}^{-}$对探针 29 也有类似的影响.
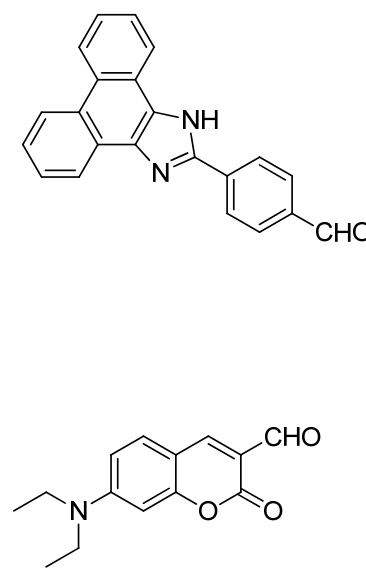

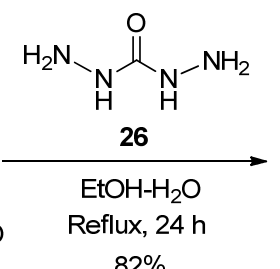

$82 \%$
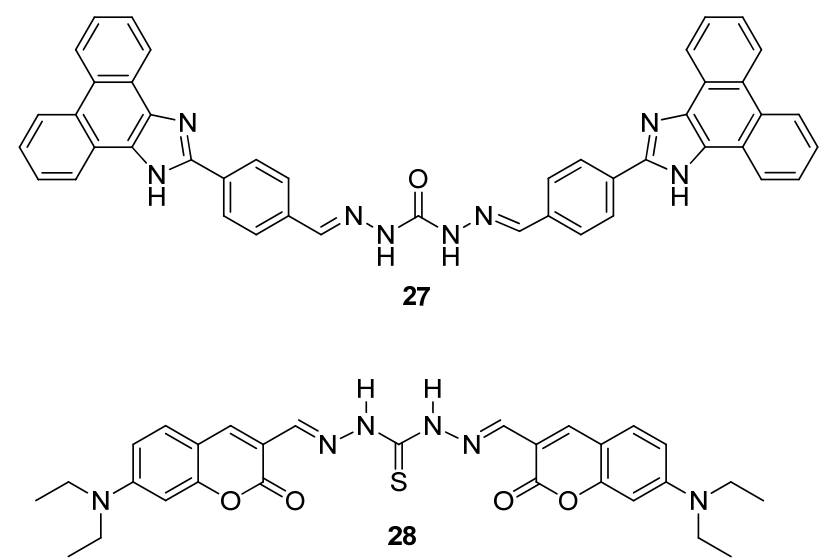

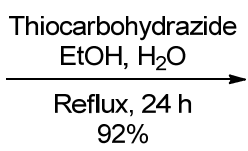
$92 \%$ 


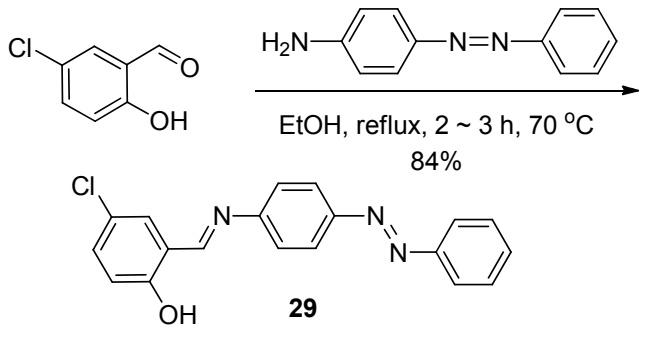

其他水杨醛衍生物也能以 $\mathrm{C}=\mathrm{N}$ 的形式构建 $\mathrm{F}^{-}$苂 光传感器, 如 Chang 等 ${ }^{[58]}$ 最近合成的 30 (Eq.16). 在传 感器 30 的 DMSO 溶液中加入 $\mathrm{F}^{-}$后, 380 和 $395 \mathrm{~nm}$ 处的 紫外吸收峰减弱, $430 \mathrm{~nm}$ 处的吸收峰增强, 344 和 410 $\mathrm{nm}$ 处出现两个等吸收点, 且裸眼可见溶液颜色由无色 变为黄色; 而 $485 \mathrm{~nm}$ 处的荧光发射峰增强. 这是因为 $\mathrm{F}^{-}$能与传感器的 $\mathrm{OH}$ 形成氢键, 继而发生去质子化, 促 进其 ICT 过程, 导致光谱的变化, 因此可实现对 $\mathrm{F}^{-}$的检 测. 30 与 $\mathrm{F}^{-}$的络合常数为 $6.1 \times 10^{4} \mathrm{~L} / \mathrm{mol}$, 检测限可达 $2.1 \times 10^{-6} \mathrm{~mol} / \mathrm{L}$.

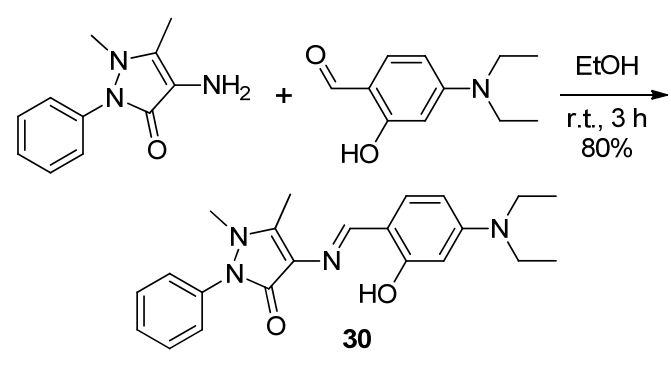

同样地, 含有羟基的萗甲醛也能基于上述酚羟基与 氟离子的作用原理而设计出含有 $\mathrm{C}=\mathrm{N}$ 键的氟离子化学 传感器. 例如, Kim 等 ${ }^{[59]}$ 以 1-羟基-2-菜甲醛和氨基乙酸 为原料, 合成了传感器 31 (Eq. 17). 在 31 的 DMSO 溶液 中加入 $\mathrm{F}^{-}, 462 \mathrm{~nm}$ 处的荧光发射峰显著增强; 而在紫外 滴定实验中, 加入 $0 \sim 2$ equiv. 的 $\mathrm{F}^{-}$, 发现其 $289 \sim 470$ $\mathrm{nm}$ 范围的紫外吸收强度有所增强, 而 $274 \mathrm{~nm}$ 处的紫外 吸收峰减弱, $289 \mathrm{~nm}$ 处出现一个等吸收点; 当加入量为 2 10 equiv. 时, 吸收光谱没有变化, 继续加入 $\mathrm{F}^{-}, 275$ 、 $328 、 435 \mathrm{~nm}$ 处的吸收峰减弱, 285 及 $412 \mathrm{~nm}$ 处的吸收 峰增强. 产生以上变化的原因, 是因为少量的 $\mathrm{F}^{-}$先使羒 基发生去质子化. 随着 $\mathrm{F}^{-}$浓度的增加, 䒺酚基团也发生 去质子化. 这两步作用, 导致光谱发生改变. 因此, 传 感器 31 可实现对 $\mathrm{F}^{-}$的检测, 检测限为 $1.80 \times 10^{-6}$ $\mathrm{mol} / \mathrm{L}$.
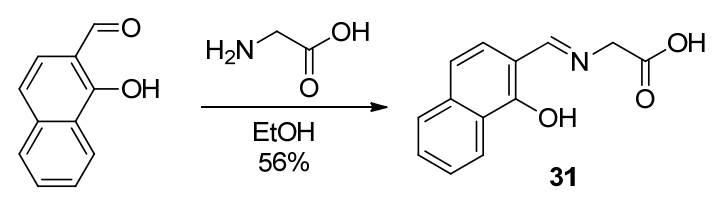

魏太保等 ${ }^{[60]}$ 以 2-羟基-1-荎甲醛(32)和 1,4-丁二胺为 原料, 合成了 $\mathrm{F}^{-}$传感器 33 (Eq. 18). 在传感器 33 的 DMSO 溶液中加入 $\mathrm{F}^{-}, 467 \mathrm{~nm}$ 处的荧光发射峰增强; 而 其紫外吸收峰从 $402 \mathrm{~nm}$ 处红移到 $423 \mathrm{~nm}$ 处, 溶液颜色 由浅黄色变为深黄色. 这是由于 $\mathrm{F}^{-}$能与传感器的 $\mathrm{OH}$ 形成氢键, 继而发生去质子化, 导致光谱改变. 其他离 子几乎没有影响, 故该传感器可以实现对 $\mathrm{F}^{-}$的检测, 检 测限可达 $1.4 \times 10^{-8} \mathrm{~mol} / \mathrm{L}$.

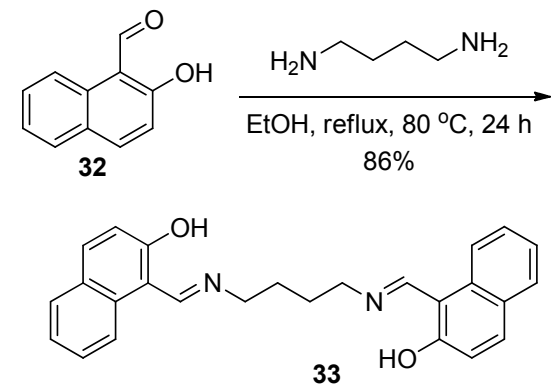

最近, 魏太保课题组 ${ }^{[61]}$ 又利用类似的原理, 以联苯 胺和 32 为原料, 合成了 “turn-off” 型 $\mathrm{F}^{-}$苂光传感器 $\mathbf{3 4}$ (Eq. 19), 其能实现对 $\mathrm{F}^{-}$的检测, 检测限为 $2.7 \times 10^{-7}$ $\mathrm{mol} / \mathrm{L}$. 值得一提的是, 加入 $\mathrm{Ca}^{2+}$ 后能使其荧光恢复, 基 于此, 研究者将 $\mathrm{F}^{-}$和 $\mathrm{Ca}^{2+}$ 作为输入信号, $520 \mathrm{~nm}$ 处的发 射峰强度作为输出信号, 设计为 IMP 的分子逻辑门. 只 有当输入 $(1,0)$ 时, $520 \mathrm{~nm}$ 处的荧光发生猝灭, 输出信号 为 “ 1 ”, 而输入其他时, $520 \mathrm{~nm}$ 处的苂光没有发生猝灭, 输出信号为 “ 0 ”.<smiles>Nc1ccc(-c2ccc(N)cc2)cc1</smiles>

菜酚醛类化合物构建的苂光探针不仅可用于体外 $\mathrm{F}^{-}$的检测, 近年来也有应用于生物活性分子内 $\mathrm{F}^{-}$检测 的报道. 例如, 刘瑞源等 ${ }^{[62]}$ 以有细胞透过性的 2-氰基乙 酸衍生物 35 与 6-羟基-2-䒺甲醛为原料进行缩合反应, 利用 $\mathrm{C}=\mathrm{C}$ 的生成, 设计合成了 $\mathrm{F}^{-}$探针 36 (Eq. 20). 在 探针 36 的磷酸缓冲盐溶液(含体积分数 $1 \% \mathrm{DMSO}$ ) 中滴 加 $\mathrm{NaF}$, 其 298 和 $382 \mathrm{~nm}$ 处的紫外吸收峰减弱, $548 \mathrm{~nm}$ 处出现新的吸收峰并逐渐增强, 且裸眼可见溶液颜色由 
无色变为粉色; 其苂光光谱也发生改变, 原 $490 \mathrm{~nm}$ 处的 发射峰发生猝灭, $450 \mathrm{~nm}$ 处出现一个新的发射峰且强度 逐渐增强. 以上光谱变化的产生是由于探针 $\mathbf{3 6}$ 中的 $\mathrm{OH}$ 与 $\mathrm{F}^{-}$以氢键结合, 继而发生去质子化, 导致光谱改变, 从而实现对 $\mathrm{F}^{-}$的检测, 其检测限可达 $8.54 \times 10^{-6} \mathrm{~mol} / \mathrm{L}$. 由于探针 36 有较好的细胞透过性, 故其还可用于活细 胞成像.
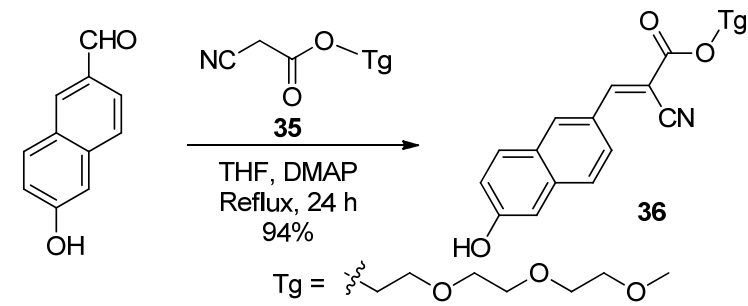

若在探针中引入苯乙烯基, 可削弱 $\mathrm{O}-\mathrm{H}$ 的酸性, 减 小碱性干扰离子的影响, 且有利于 ICT 过程的进行, 如 $\mathrm{Lu}$ 等 ${ }^{[63]}$ 设计合成的荧光探针 37 (Eq. 21). $\mathrm{F}^{-}$的加入, 使 37 的紫外吸收峰从 $427 \mathrm{~nm}$ 处红移到 $641 \mathrm{~nm} ; 582 \mathrm{~nm}$ 处 的苂光发射峰发生猝灭, 且日光灯下溶液颜色从黄色变 为深蓝色, 其对 $\mathrm{F}^{-}$检测限为 $1.42 \times 10^{-5} \mathrm{~mol} / \mathrm{L}$. 不仅如 此, 由于 37 荧光强度在含蛋白质的酸性环境中会增强, 故可作为溶酶体标记试剂而用于癌细胞研究.
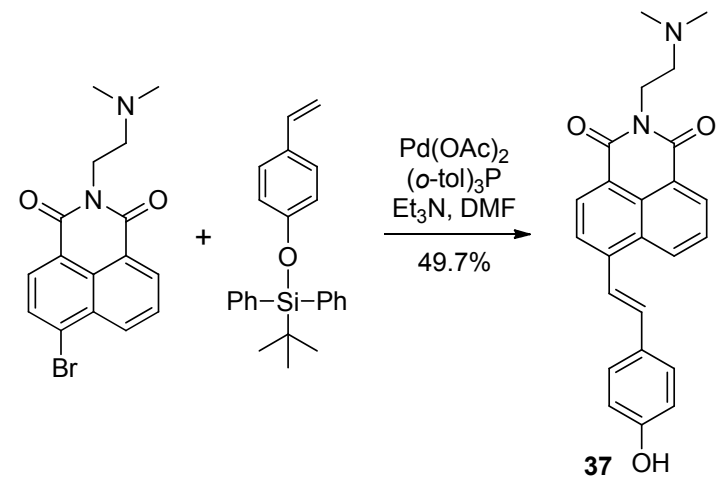

与此同时, 酚羟基邻位含有氮杂环的传感器设计, 近年来也被引起关注. 例如, Landge 等 ${ }^{[6]}$ 以苯乙炔和 2叠氮苯酚为原料, 设计合成了可用于 $\mathrm{F}^{-}$检测的 “turn-on” 型传感器 38 (Eq. 22). 向 $\mathbf{3 8}$ 的 $\mathrm{CH}_{3} \mathrm{CN}$ 溶液中 加入 $F^{-}, 290 \mathrm{~nm}$ 处的紫外吸收峰强度减弱, $345 \mathrm{~nm}$ 处的 紫外吸收峰增强; 原 $330 \mathrm{~nm}$ 的荧光发射峰发生猝灭, $430 \mathrm{~nm}$ 处产生新的荧光发射峰并且强度逐渐增强. 这

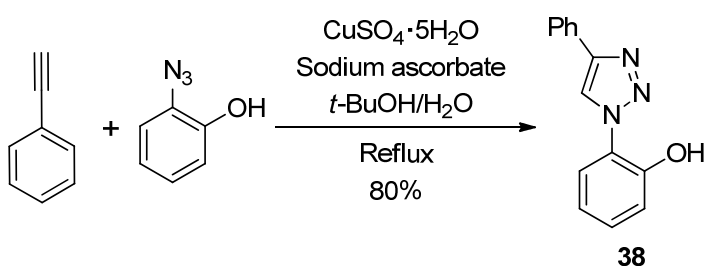

是因为 $\mathrm{F}^{-}$和 $\mathrm{OH}$ 以氢键形式结合，继而发生去质子化, 引起光谱的改变. 其他离子所引起的变化非常微弱, 故 38 可实现对 $\mathrm{F}^{-}$的选择性检测.

非酚羟基也能与 $\mathrm{F}^{-}$发生去质子化而应用于 $\mathrm{F}^{-}$的选 择性检测 ${ }^{[65]}$. 例如, Mahapatra 等 ${ }^{[66]}$ 以 4-羟基香豆素和 3硝基苯甲醛为原料, 合成了 $\mathrm{F}^{-}$苂光探针 39 (Scheme 10), 其机理就是 $\mathrm{F}^{-}$与 39 的 $\mathrm{OH}$ 先以氢键结合, 进一步发生 去质子化作用, 导致光谱性质及溶液颜色发生改变. 其 他离子几乎没有影响, 故探针 39 能实现对 $\mathrm{F}^{-}$的高选择 性和高灵敏性检测, 络合常数为 $3.07 \times 10^{3} \mathrm{~L} / \mathrm{mol}$, 检测 限可达 $3.0 \times 10^{-6} \mathrm{~mol} / \mathrm{L}$.
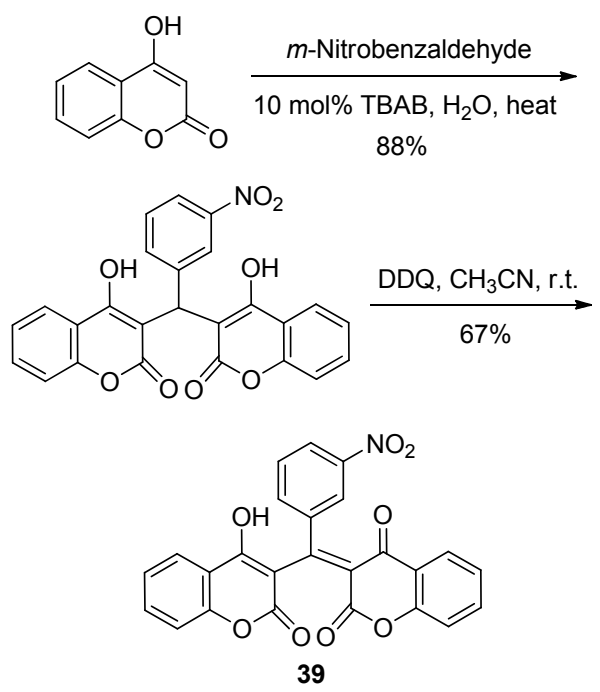

图式 10 探针 39 的合成

Scheme 10 Synthesis of probe 39

\subsection{2 $\mathrm{OH}$ 与 $\mathrm{NH}$ 共存型的去质子化}

在探针中同时引入 $\mathrm{OH}$ 与 $\mathrm{NH}$, 也能实现对 $\mathrm{F}^{-}$的高 效检测 ${ }^{[67,68]}$. 例如, Thomas 等 ${ }^{[69]}$ 合成了苂光传感器 $\mathbf{4 0}$ (Eq. 23), 向 40 的 $\mathrm{CH}_{3} \mathrm{CN}$ 溶液中加入 $\mathrm{F}^{-}$，其 $342 \mathrm{~nm}$ 处 的紫外吸收峰减弱, $404 \mathrm{~nm}$ 处产生新的吸收峰, $377 \mathrm{~nm}$ 处有等吸收点出现, 溶液颜色由无色变为亮黄色; 431 $\mathrm{nm}$ 处的苂光发射峰红移到 $489 \mathrm{~nm}$ 处. 这是因为 $\mathrm{F}^{-}$能与 传感器的 $\mathrm{NH}$ 和 $\mathrm{OH}$ 形成氢键, 进一步发生去质子化作 用, 导致光谱发生改变, 从而实现对 $\mathrm{F}^{-}$的检测, 检测限 可达 $3.0 \times 10^{-8} \mathrm{~mol} / \mathrm{L}$. 不足的是, 在上述 $\mathrm{CH}_{3} \mathrm{CN}$ 溶液中 检测时加入 $\mathrm{AcO}^{-}$也能使传感器 $\mathbf{4 0}$ 发生类似的改变, 但 是在 $\mathrm{CH}_{3} \mathrm{CN}$ 和 $\mathrm{MeOH}$ 的混合溶液中, 传感器 $\mathbf{4 0}$ 与 $\mathrm{AcO}^{-}$作用减弱, 对 $\mathrm{F}^{-}$表现出高的选择性.

近来, Pascu 等 ${ }^{[70]}$ 以荎二甲酰亚胺肼化合物和水杨 醛为原料合成了 $\mathrm{F}^{-}$探针 41 (Eq. 24). 在探针 41 的 $\mathrm{CH}_{3} \mathrm{CN}$ 溶液中加入 $\mathrm{F}^{-}$，探针分子的 $\mathrm{NH}$ 和 $\mathrm{OH}$ 通过氢键 与其结合，接着都发生去质子化作用，导致光谱发生改 变, 从而实现探针 41 对 $\mathrm{F}^{-}$的检测. 


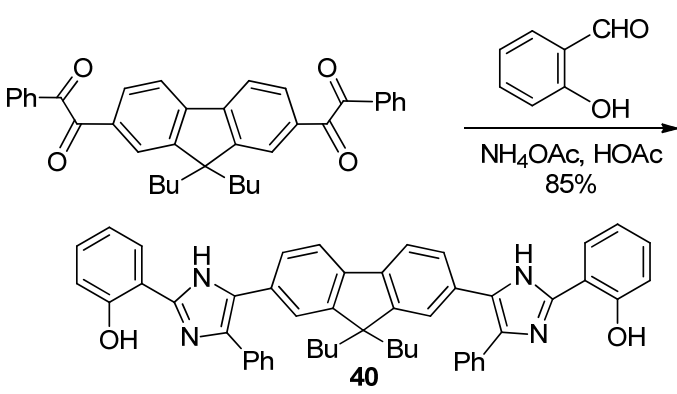<smiles>CCCN1C(=O)c2cccc3c(NN)ccc(c23)C1=O</smiles><smiles>CCO[AsH3]</smiles><smiles>CCCN1C(=O)c2cccc3c(N/N=C/c4ccccc4O)ccc(c23)C1=O</smiles>

2015 年, Chellappa 等 ${ }^{[71]}$ 引入硝基偶氮苯作为显色 基, 苯并咪唑作为荧光团, 合成了 “turn-on” 型 $\mathrm{F}^{-}$苂光 探针 42 (Scheme 11). 在 42 的 DMSO 溶液中加入 $F^{-}$, 其 紫外吸收峰发生蓝移, 在 523 和 $655 \mathrm{~nm}$ 出现了等吸收 点; 而其 $423 \mathrm{~nm}$ 处的荧光发射峰强度增强, 在日光灯下 溶液颜色由粉红色变为紫色, 这是由于 $\mathrm{F}^{-}$能与传感器 的 $\mathrm{NH}$ 和 $\mathrm{OH}$ 形成氢键, 继而使 $\mathrm{OH}$ 发生脱质子化, 影 响了 ICT 过程, 导致光谱的改变. 其他离子的加入对光 谱几乎没有影响, 故探针 42 可实现对 $\mathrm{F}^{-}$的检测, 络合 常数为 $6.96 \times 10^{3} \mathrm{~L} / \mathrm{mol}$, 检测限为 $9.19 \times 10^{-8} \mathrm{~mol} / \mathrm{L}$.<smiles>O=Cc1cc(/N=N/c2ccc([N+](=O)[O-])cc2)ccc1O</smiles>

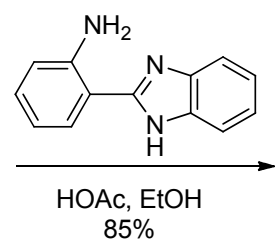<smiles>CC(C)(C)C(C)(C)C</smiles><smiles>O=[N+]([O-])c1ccc(/N=N/c2ccc3c(c2)C(c2ccccc2)N(Cc2ccccc2)c2ccccc2-3)cc1</smiles>

图式 11 探针 42 的合成及其作用机理

Scheme 11 Synthesis of probe $\mathbf{4 2}$ and its mechanism

基于水杨醛原料, Pitchumani 等 ${ }^{[72]}$ 合成了 “turn-on”
型氟离子苂光传感器 43 , 其检测机理是 $\mathrm{F}^{-}$能与 $\mathrm{NH}$ 和 $\mathrm{OH}$ 以氢键的形式结合，激活 ESIPT 过程, $\mathrm{OH}$ 脱去质子, 接着 $\mathrm{O}^{-}$与 $\mathrm{NH}$ 形成稳定的分子内氢键(Scheme 12), 这 导致其在 $361 、 312$ 和 $238 \mathrm{~nm}$ 处产生三个新的紫外吸收 峰, 肉眼可见溶液由无色变为黄色; 而其苂光发射峰也 发生明显变化, 原本只在 $426 \mathrm{~nm}$ 处有弱的发射峰, 加入 $\mathrm{F}^{-}$后, $566 \mathrm{~nm}$ 处产生新的强峰. 因此, 该传感器可实现 对 $\mathrm{F}^{-}$的检测，检测限达 $5 \times 10^{-11} \mathrm{~mol} / \mathrm{L}$, 响应时间小于 1 s. 不仅如此, 传感器 43 还可对各种水样中的 $\mathrm{F}^{-}$实现定 量分析.<smiles>COc1ccccc1C1CC(=O)c2ccccc2N1</smiles><smiles>[B]=C</smiles><smiles>Cc1ccc(Oc2ccccc2)c(C2CC(=O)c3ccccc3N2)c1</smiles><smiles>O=C1CC2c3ccccc3[C@@H]3[CH][C@H](O3)N2c2ccccc21</smiles>

图式 12 传感器 $\mathbf{4 3}$ 的作用机理

Scheme 12 Mechanism of sensor 43

类似地, Luxami 等 ${ }^{[73]}$ 以水杨醛为原料, 与 3,4-二氨 基二苯甲酮缩合，制备了 $\mathrm{F}^{-}$苂光探针 44 (Eq. 25). 向探 针 44 的 $\mathrm{CH}_{3} \mathrm{CN}$ 溶液中加入 $\mathrm{F}^{-}$，原 262 和 $335 \mathrm{~nm}$ 处的 紫外吸收峰逐渐减弱, 280 和 $360 \mathrm{~nm}$ 处产生新的吸收峰, 在 340 和 $270 \mathrm{~nm}$ 处出现等吸收点; $540 \mathrm{~nm}$ 处的荧光发 射峰发生猝灭, 在 $420 \mathrm{~nm}$ 处产生新的发射峰. 这是由于 加入 $\mathrm{F}^{-}$后, 与 $\mathrm{OH}$ 形成氢键, 继而发生去质子化作用, 抑制了 ESIPT 过程. 基于以上光谱特性的改变, 44 可实 现对 $\mathrm{F}^{-}$的选择性检测.

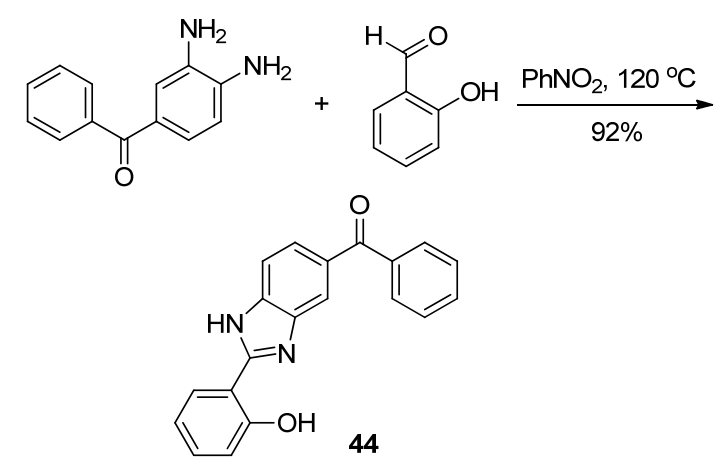

姜世梅等 ${ }^{[74]}$ 基于水杨醛原料合成了 $\mathrm{F}^{-}$苂光探针 45 (Eq. 26). 在该探针的 DMSO 溶液中加入 $F^{-}$, 原 $359 \mathrm{~nm}$ 
处的紫外吸收峰逐渐减弱, $448 \mathrm{~nm}$ 处产生新的吸收峰, $396 \mathrm{~nm}$ 处有一个等吸收点出现, 裸眼可见溶液颜色由 无色变黄色. 此外, $\mathrm{F}^{-}$的加入也使探针的苂光光谱发生 改变, $538 \mathrm{~nm}$ 处的发射峰显著增强, 紫外灯下可观察到 原本无荧光现象的溶液产生绿色荧光. 产生以上光谱变 化的原因是, $\mathrm{F}^{-}$能与探针分子的 $\mathrm{NH}$ 和 $\mathrm{OH}$ 以氢键形式 结合, 进一步发生去质子化作用, 抑制了其 ESIPT 过程, 导致光谱发生改变. 因此, 探针 45 可以实现对 $\mathrm{F}^{-}$的检 测，检测限可达 $1.09 \times 10^{-6} \mathrm{~mol} / \mathrm{L}$.

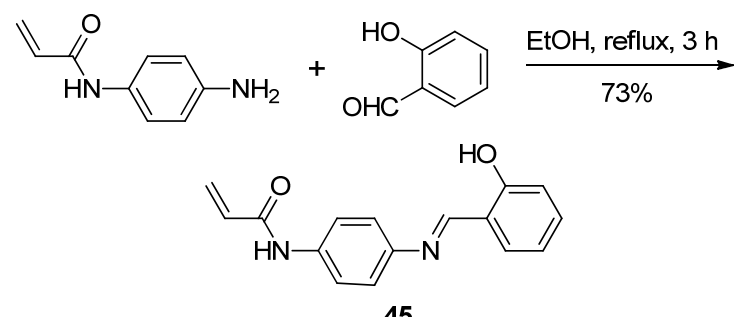

\section{3 其他类型的去质子化}

某些芳香环 $\mathrm{CH}$ 在特定的环境下, 也可与氟离子作 用形成氢键 ${ }^{[75]}$, 并发生去质子化. 例如, $\mathrm{Xu}$ 等 ${ }^{[76]}$ 用 2,3二氨基䒬和甲酸合成萗并咪唑, 再通过苄基澳, 在荎并 咪唑上引入两个富电子的苯环, 合成了基于荎并咪唑的 $\mathrm{F}^{-}$探针 46 (Scheme 13). 在 46 的 $\mathrm{CH}_{3} \mathrm{CN}$ 溶液中加入 $\mathrm{F}^{-}$, $325 \mathrm{~nm}$ 处的紫外吸收峰逐渐减弱, $347 \mathrm{~nm}$ 处吸收峰增 强; 而在荧光滴定中, 随着 $\mathrm{F}^{-}$增加, $438 \mathrm{~nm}$ 处的发射峰 减弱, $373 \mathrm{~nm}$ 产生新的发射峰并显著增强. 这是因为在 $\mathrm{F}^{-}$浓度低的溶液中, 探针先与 $\mathrm{F}^{-}$通过氢键结合, 再随着 $\mathrm{F}^{-}$浓度的增大而发生去质子化作用，并发生加成反应， 影响了 ICT 过程, 导致光谱发生改变.<smiles>Nc1cc2ccccc2cc1N</smiles>
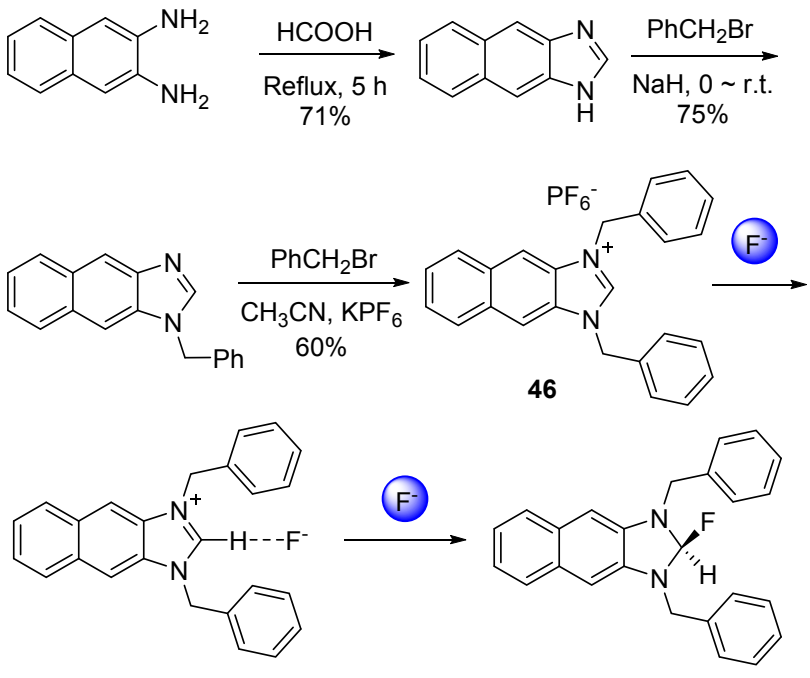

图式 13 探针 46 的合成及其作用机理 Scheme 13 Synthesis of probe $\mathbf{4 6}$ and its mechanism

\section{2 反应型的氟离子荧光探针}

氟离子易与许多探针化合物触发高选择性的反应, 引起化合物光谱性质变化, 从而实现对氟离子的检测. 因此，近年来不断有反应型的氟离子苂光探针被设计与 合成. 值得注意的是, 氢键型探针大多只能识别有机来 源的氟离子(如 TBAF), 而反应型苂光探针不但能够识 别有机来源的氟离子, 而且往往能够识别无机来源的氟 离子(如 $\mathrm{NaF})$.

\section{1 基于 $\mathrm{Si}-\mathrm{O}$ 键的反应型探针}

氟离子与硅原子具有较强的相互作用, 可形成稳定 的 $\mathrm{Si}-\mathrm{F}$ 键. 在 $\mathrm{F}^{-}$的作用下, 许多有机硅氧化合物易发 生脱硅化反应, 导致化学结构发生变化 ${ }^{[77]}$, 从而引起荧 光性质的改变. 因此，近年来不少研究者设计合成了基 于 $\mathrm{Si}-\mathrm{O}$ 键的荧光探针，应用于 $\mathrm{F}^{-}$的检测 ${ }^{[78]}$. 按照以不 同的氯硅烷原料构建有机硅氧化合物的方法进行分类, 基于 $\mathrm{Si}-\mathrm{O}$ 键的苂光探针也有很多类型.

\section{1 .1 叔丁基二甲基硅基类}

叔丁基二甲基氯硅烷(TBDMS-Cl)是常见的 $\mathrm{OH}$ 保 护试剂，因此其常常以叔丁基二甲基硅基(TBDMS)的 形式引入到氟离子苂光探针中去. 例如, Weiss 等 ${ }^{[79]}$ 以 5甲基-4-着基-2-(2-吡啶)噻唑和 TBDMS-Cl 为原料, 合成 了可用于检测 $\mathrm{F}^{-}$的荧光探针 47 (Eq. 27). 在 47 的 DMSO 溶液中加入 $\mathrm{F}^{-}, 418 \mathrm{~nm}$ 处的苂光发射峰发生猝 灭, $602 \mathrm{~nm}$ 处产生新的发射峰并逐渐增强. 这是因为 $\mathrm{F}^{-}$ 的加入引发了 $\mathrm{Si}-\mathrm{O}$ 键的断裂, 促使化合物转变为烯醇 式构型，导致荧光性质发生改变，从而实现对 $\mathrm{F}^{-}$的检 测，检测限可低至 $1 \times 10^{-7} \mathrm{~mol} / \mathrm{L}$.

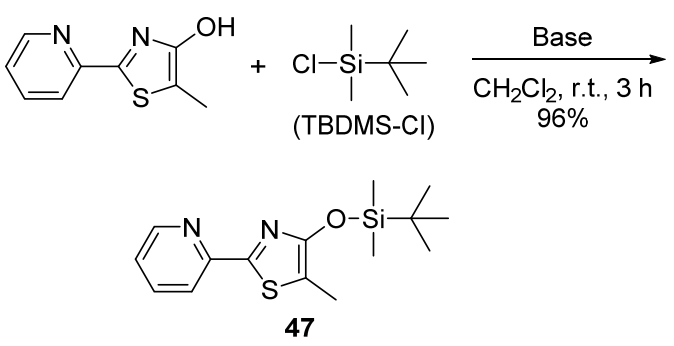

以 TBDMS 作为保护基的苂光探针不仅可用于检测 体外的 $\mathrm{F}^{-}$, 近年来也有将其应用于生物活性分子检测 的报道. 例如, Wang 等 ${ }^{[80]}$ 以具有良好生物相容性的 6-差弪 基苯并噻唑类化合物 48 为起始原料, 先与生物性原料 氨基葡萄糖反应以增强目标分子的水溶性，再将酚 $\mathrm{OH}$ 硅烷基化，通过这一系列反应，合成 “turn-on” 型 $\mathrm{F}^{-}$荧 光探针 49 (Scheme 14). 在探针的磷酸盐缓冲液(含 $0.5 \%$ DMSO)中加入 NaF，探针脱去 TBDMS，使其 $508 \mathrm{~nm}$ 处 的苂光发射峰显著增强, 相比之下其他离子均没有响 


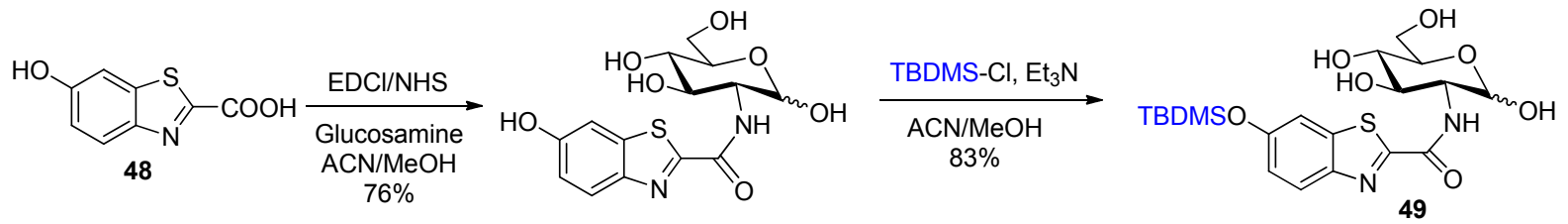

图式 14 探针 49 的合成

Scheme 14 Synthesis of probe 49

应, 故该探针可实现对 $\mathrm{F}^{-}$的检测, 检测限为 $1.18 \times 10^{-7}$ $\mathrm{mol} / \mathrm{L}$. 此外, 探针有较好的生物相容性, 且无细胞毒 性，故还可应用于细胞成像.

Talukdar 等 ${ }^{[81]}$ 利用含 TBDMS 结构的化合物 $\mathbf{5 0}$ 和 荧光素类化合物为原料, 合成了荧光探针 51 (Scheme 15). 在 51 的 DMSO 溶液中加入 $\mathrm{F}^{-}$, 其在 $523 \mathrm{~nm}$ 处的 荧光发射峰随 $\mathrm{F}^{-}$浓度增大而逐步增强, 肉眼可见溶液 颜色由无色变为黄色, 紫外灯下溶液发出绿色苂光. 这 是由于在 $\mathrm{F}^{-}$的诱导下, $\mathbf{5 1}$ 中 $\mathrm{Si}-\mathrm{O}$ 键断裂而脱去 TBDMS，且经成环反应释放出邻羟甲基苯甲酸内酯， 同时生成荧光化合物 52, 导致荧光增强. 基于此, 探针 可实现对 $\mathrm{F}^{-}$的检测, 检测限可达 $1.03 \times 10^{-6} \mathrm{~mol} / \mathrm{L}$. 此 外，探针 51 还可用于细胞成像.

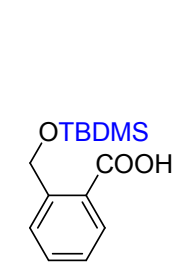

50
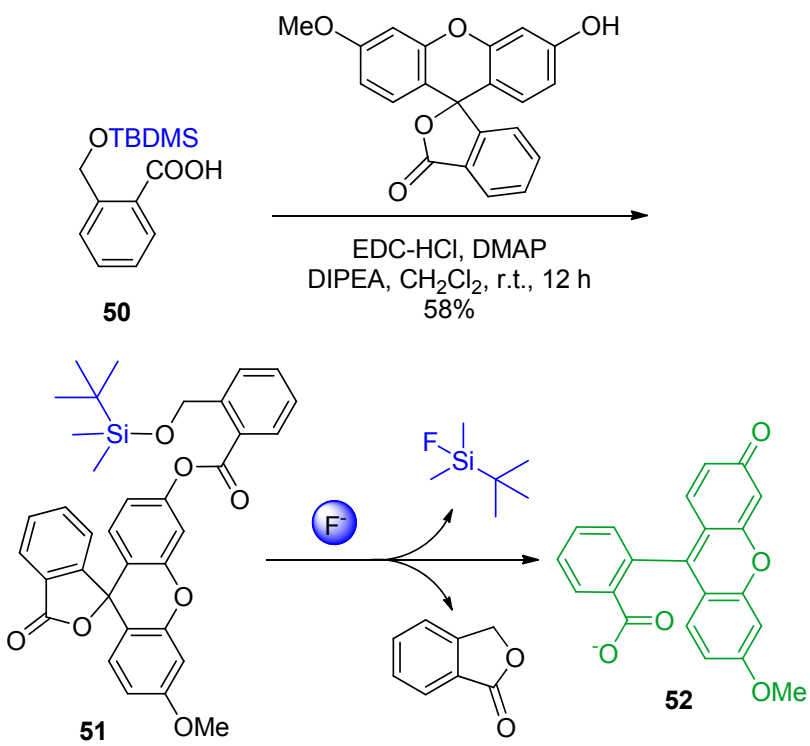

图式 15 探针 51 的合成及其作用机理

Scheme 15 Synthesis of probe $\mathbf{5 1}$ and its mechanism

利用同样的检测机理, Talukdar 课题组 ${ }^{[82]}$ 还以 50 与 化合物 53 为原料, 合成了 $\mathrm{F}^{-}$苂光探针 54 (Scheme 16). 向 54 的 THF 溶液中加入 $F^{-}, 347$ 和 $437 \mathrm{~nm}$ 处的紫外吸 收峰减弱, 550、573、591 nm 处产生新的吸收峰; $595 \mathrm{~nm}$ 处的苂光发射峰增强, 且肉眼可见溶液由黄色变为粉 色，其对 $\mathrm{F}^{-}$的检测限可达 $6 \times 10^{-8} \mathrm{~mol} / \mathrm{L}$.

此外, Talukdar 课题组 ${ }^{[83]}$ 还利用 4-叔丁基二甲基硅

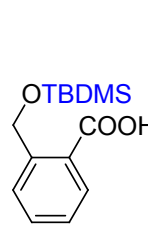

50

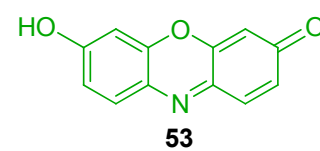

EDC. $\mathrm{HCl}, \mathrm{DMAP}$, DIPEA $\mathrm{CH}_{2} \mathrm{Cl}_{2}$, r.t., $12 \mathrm{~h}$

$50 \%$

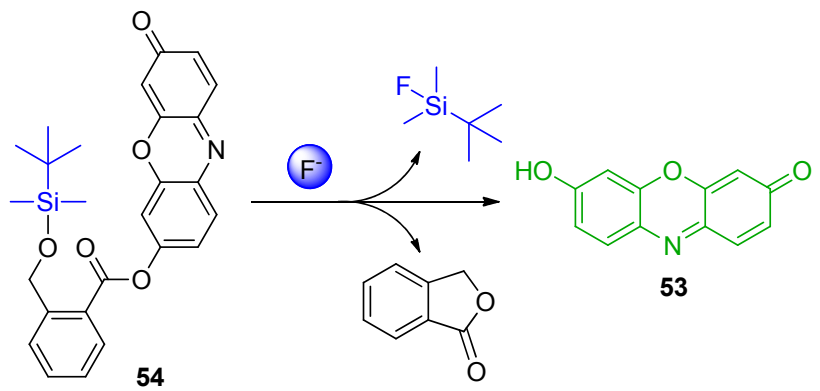

图式 16 探针 54 的合成及其作用机理

Scheme 16 Synthesis of probe 54 and its mechanism

氧基苯甲醇 55 和硝基苯并噁二唑胺反应，以 $37 \%$ 的产 率合成了 $\mathrm{F}^{-}$苂光探针 56 (Eq. 28), 其亦可应用于细胞成 像.
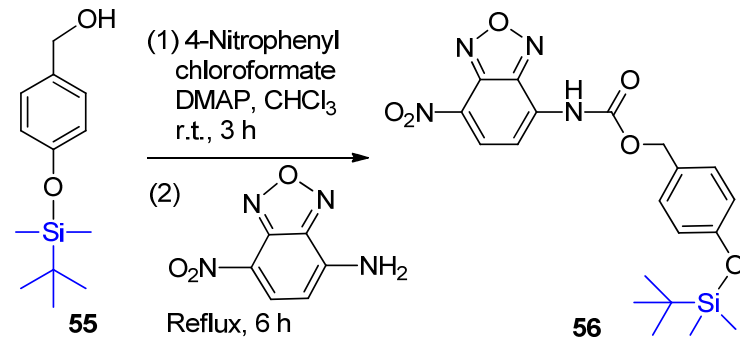

(28)

汤新景等 ${ }^{[84]}$ 也以化合物 $\mathbf{5 5}$ 为原料，成功地以 $51 \%$ 的总产率合成了苂光探针 57 (Eq. 29), 并将其成功应用 于小鼠体内 $\mathrm{F}^{-}$的活细胞成像.

各种基于荧光酚类化合物释放而应用于氟离子检 测的探针报道还有很多. 例如, Akkaya 等 ${ }^{[85]}$ 合成了探针 58 (Scheme 17), 在其 DMSO 溶液中加入 $\mathrm{F}^{-}$时, 随着 TBDMS 的脱去和二氧杂环丁烷结构的裂解，能发出明 亮的蓝色荧光; 而宋相志等 ${ }^{[86]}$ 设计合成了基于 6 -乙酰 基-2-菜酚的“turn-on”型 $\mathrm{F}^{-}$苂光探针 59 (Scheme 18), 检 测限可达 $4 \times 10^{-8} \mathrm{~mol} / \mathrm{L}$, 响应时间为 $3 \mathrm{~min}$. 
<smiles>O=C(Cl)Nc1ccc2c3c(cccc13)C(=O)OC2=O</smiles>

(1) $55, \mathrm{CH}_{2} \mathrm{Cl}_{2}$, r.t., $3 \mathrm{~h}$

(2) (3-aminopropyl)triphenylphosphonium bromide, $\mathrm{MeOH}$<smiles>CCOc1ccc(COC(=O)Nc2ccc3c4c(cccc24)C(=O)N(CCC[Pb](Br)(c2ccccc2)c2ccccc2)C3=O)cc1</smiles>

利用各种水杨醛衍生物构建 TBDMS 类的氟离子探
针也很常见，而且其作用机理中涉及进一步的成环反 应. 例如, 宋相志等 ${ }^{[87}$ 将化合物 60 引入 TBDMS 后, 再 与丙二腈反应缩合, 合成了 $\mathrm{F}^{-}$苂光探针 61 (Scheme 19). 在 HEPES 缓冲液 (含 $30 \% \mathrm{CH}_{3} \mathrm{CN}$ ) 中加入 $\mathrm{NaF}, \mathrm{Si}-\mathrm{O}$ 键 断裂, 随后发生分子内环合, 转变为亚氨基香豆素结构. 这一结构的转变, 引起其紫外吸收峰蓝移, 而 $616 \mathrm{~nm}$ 处 产生一个强的荧光发射峰. 基于以上光谱变化, 该探针 可实现对 $\mathrm{F}^{-}$的检测, 检测限为 $5.4 \times 10^{-6} \mathrm{~mol} / \mathrm{L}$, 响应时 间小于 $10 \mathrm{~min}$. 此外, 探针 $\mathbf{6 1}$ 还可应用于细胞成像.

类似地, 王静云等 ${ }^{[88]}$ 以含稠环结构的水杨醛衍生 物 62 为原料, 合成了探针 63 (Scheme 20). 在探针 63 的 $\mathrm{CH}_{3} \mathrm{CN}$ 溶液中加入 $\mathrm{F}^{-}$, 紫外吸收峰发生蓝移, 在 485 $\mathrm{nm}$ 处苂光发射峰显著增强, 其对 $\mathrm{F}^{-}$的检测限为 $1.69 \times$ $10^{-7} \mathrm{~mol} / \mathrm{L}$.

其实, 以非稠环结构的水杨醛衍生物 64 为原料, 也

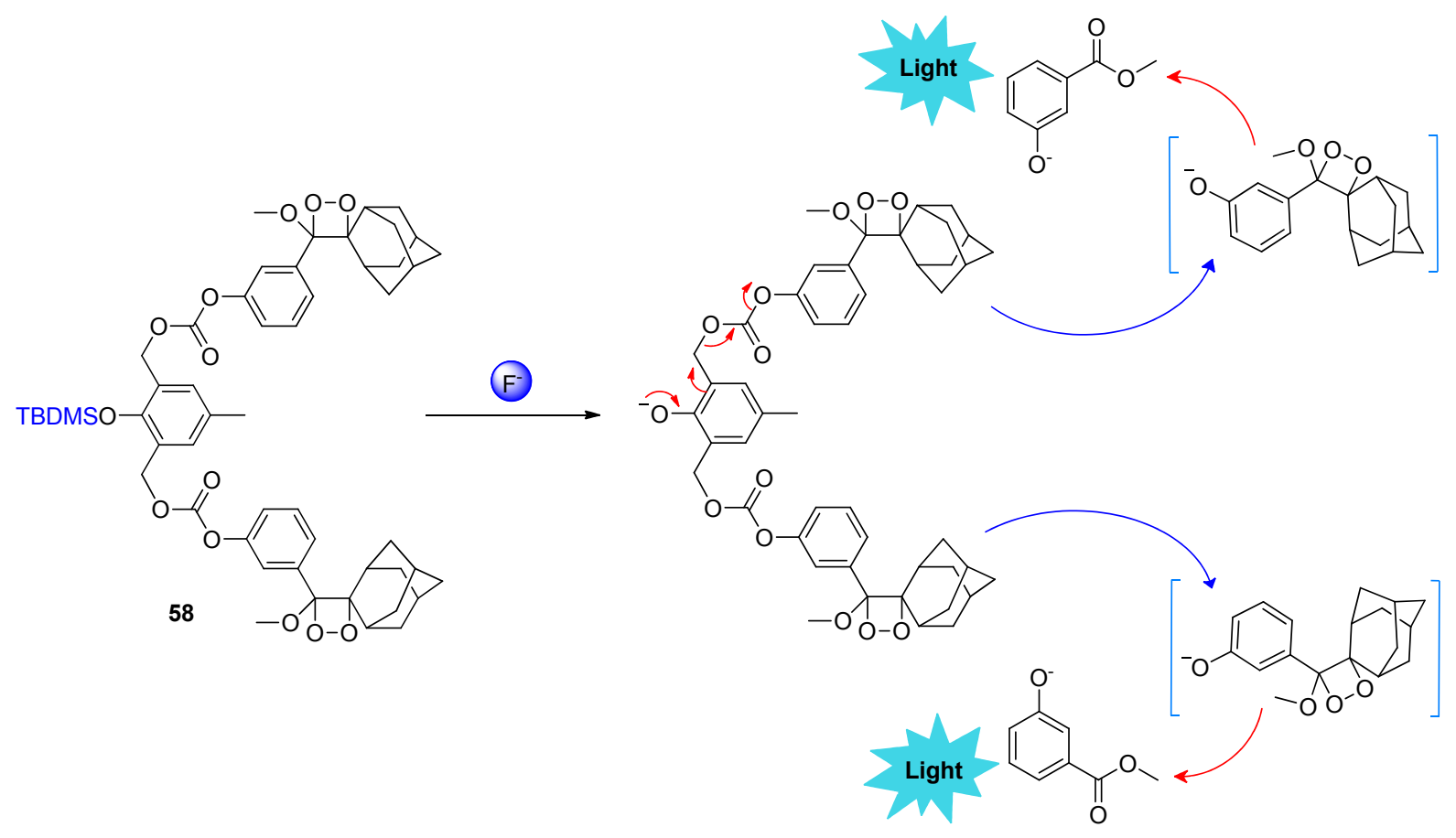

图式 17 探针 $\mathbf{5 8}$ 的作用机理

Scheme 17 Mechanism of probe $\mathbf{5 8}$
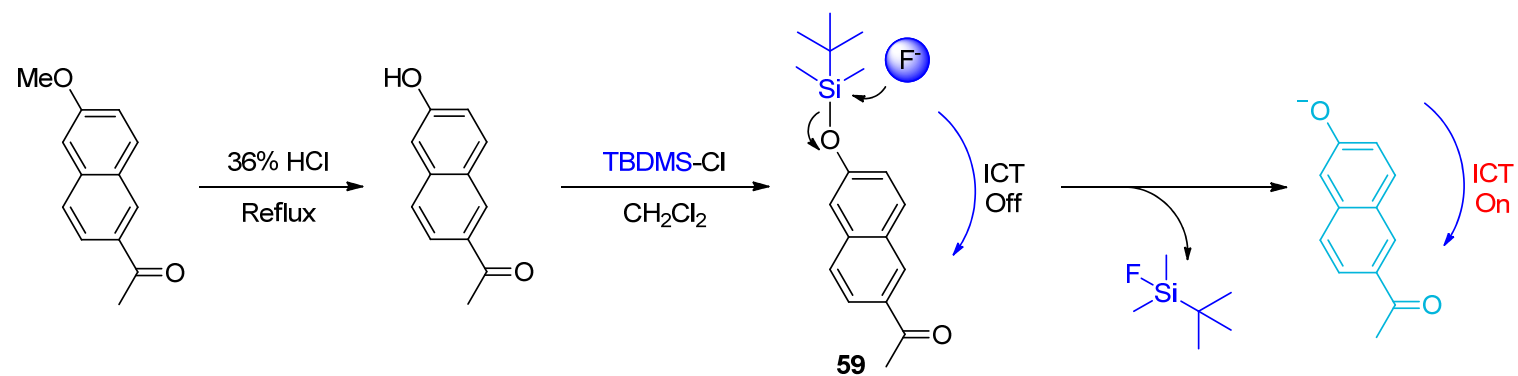

图式 18 探针 59 的合成与作用机理

Scheme 18 Synthesis of probe $\mathbf{5 9}$ and its mechanism 

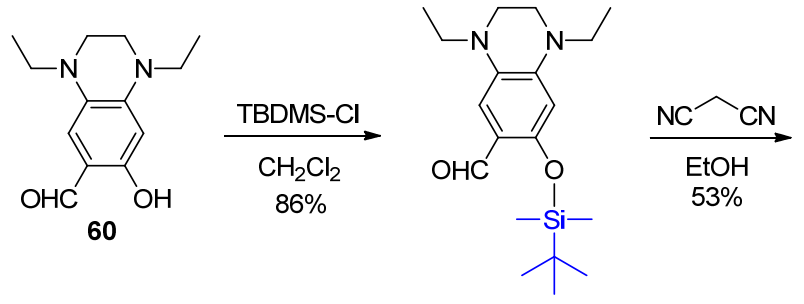
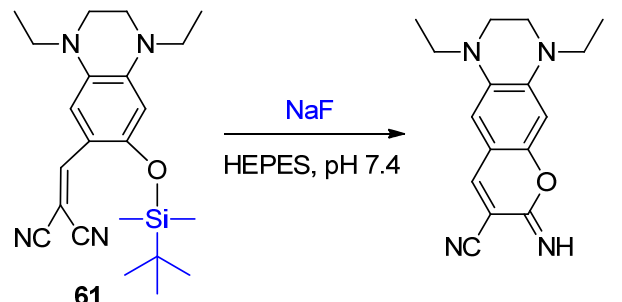

图式 19 探针 61 的合成及其作用机理

Scheme 19 Synthesis of probe 61 and its mechanism
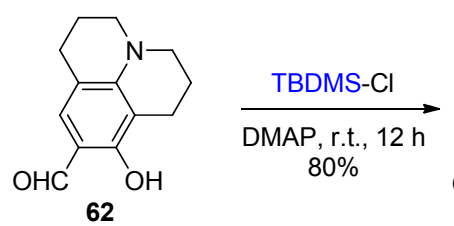

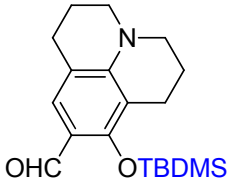

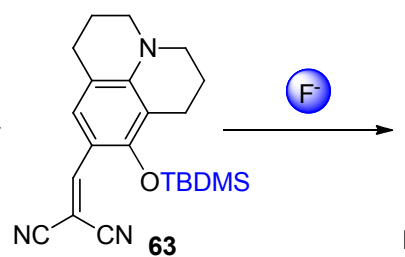

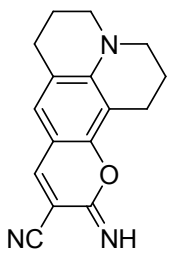

图式 20 探针 63 的合成及其作用机理

Scheme 20 Synthesis of probe $\mathbf{6 3}$ and its mechanism

可利用类似的原理构建氟离子检测探针, 但需要对用于 缩合的腈类化合物进行结构改造, 以利于亚氨基香豆素 结构更好地形成离域 $\pi$ 键, 如彭羽等 ${ }^{[89]}$ 以 2-苯并噻唑乙 腈进行缩合而合成的荧光探针 65 (Scheme 21), 其可实 现对 $\mathrm{F}^{-}$的高选择性检测, 检测限为 $1.18 \times 10^{-7} \mathrm{~mol} / \mathrm{L}$. 不仅如此, 65 也可对 $\mathrm{NaF}$ 实现检测.

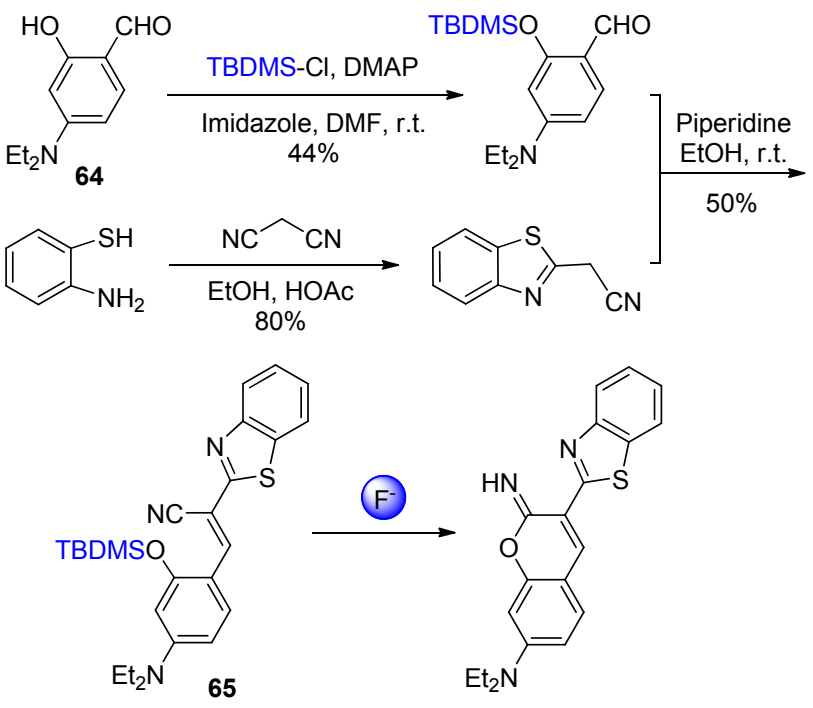

图式 21 探针 65 的合成及其作用机理

Scheme 21 Synthesis of probe $\mathbf{6 5}$ and its mechanism

此外, 如果将 65 与氧化石墨烯进行组装, 可得到氧 化石墨烯辅助的新荧光探针, 用于检测 $\mathrm{F}^{-}$时能大大缩 短响应时间(由原来的 $4 \mathrm{~h}$ 减少到 $30 \mathrm{~min}$ ), 检测限约为 $3.0 \times 10^{-7} \mathrm{~mol} / \mathrm{L}$, 且可用于细胞成像 ${ }^{[90]}$.

除了上述的单作用位点外, 还可同时引入两个 TBDMS 基, 合成 $\mathrm{F}^{-}$苂光探针. 最近, 李天铎等 ${ }^{[1]}$ 以 4叔丁基二甲基硅氧基苯胺和尿素为原料, 合成了传感器
66 (Eq. 30). 在传感器的 $\mathrm{DMSO} / \mathrm{H}_{2} \mathrm{O}(V / V=95 / 5)$ 溶液中 加入 $\mathrm{F}^{-}$, 其 $265 \mathrm{~nm}$ 处的紫外吸收峰大幅度增强; 而其 在 $347 \mathrm{~nm}$ 处的苂光发射峰也逐渐增强. 这是因为在 $F^{-}$ 的作用下, 传感器的 $\mathrm{Si}-\mathrm{O}$ 键断裂, TBDMS 基离去, 导 致光谱发生改变. 因此, 传感器 $\mathbf{6 6}$ 能实现对 $\mathrm{F}^{-}$的检测, 检测限达 $4.84 \times 10^{-8} \mathrm{~mol} / \mathrm{L}$.

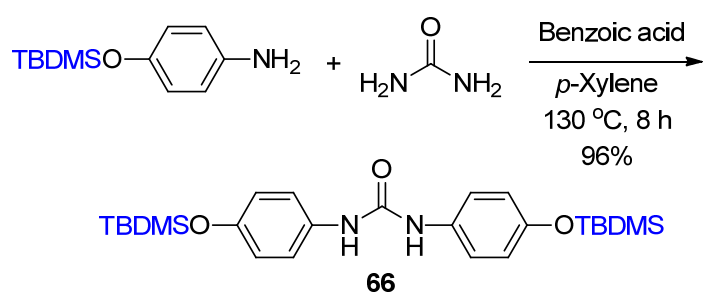

\subsection{2 叔丁基二苯基硅基类}

除了叔丁基二甲基硅基(TBDMS), 还可利用叔丁 基二苯基氯硅烷(TBDPS-Cl)引入叔丁基二苯基硅基 (TBDPS), 合成氟离子荧光探针 ${ }^{[92]}$. 例如, 李振等 ${ }^{[33]}$ 从 苂光素出发, 在苂光素衍生物 67 上引入 TBDPS, 以 $55 \%$ 的总产率合成了 “turn-on” 型 $\mathrm{F}^{-}$荧光探针 68 (Scheme 22). 在 $\mathbf{6 8}$ 的 HEPES 缓冲溶液(含 10\% THF) 中加入 $\mathrm{NaF}$ ，探针分子中的 $\mathrm{Si}-\mathrm{O}$ 键断裂，导致 $520 \mathrm{~nm}$ 处的荧光发射峰显著增强, 紫外灯下溶液发出绿色荧 光, 故能实现对 $\mathrm{F}^{-}$的检测, 检测限可达 $1.8 \times 10^{-5}$ $\mathrm{mol} / \mathrm{L}$. 此外, 探针 $\mathbf{6 8}$ 还被成功应用于 HeLa 细胞中 $\mathrm{F}^{-}$ 的检测.

异硫氰基苂光素先与甲氧基聚乙二醇胺反应，再与 TBDPS-Cl 反应, 可合成聚合物型 $\mathrm{F}^{-}$传感器 69 (Eq. 31), 其能在 $100 \%$ 水溶液中实现对 $\mathrm{NaF}$ 的检测, 对 $\mathrm{F}^{-}$的检测 限可达 $4.5 \times 10^{-7} \mathrm{~mol} / \mathrm{L}$, 响应时间小于 $10 \mathrm{~min}$, 且在细 
<smiles>O=C(O)c1ccccc1-c1c2ccc(=O)cc-2oc2cc(O)ccc12</smiles>

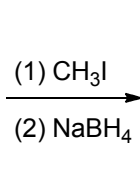<smiles>COC(=O)c1ccccc1C1c2ccc(O)cc2Oc2cc(O)ccc21</smiles>

67

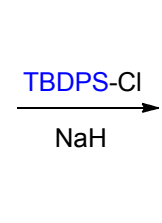<smiles>COC(=O)c1ccc2c(c1)Oc1cc(OC)ccc1C2c1ccccc1C(=O)OC</smiles>

68

图式 22 探针 68 的合成

Scheme 22 Synthesis of probe 68<smiles>O=C1OC2(c3ccc(O)cc3Oc3cc(O)ccc32)c2ccc(N=C=S)cc21</smiles>

(1) $\mathrm{O} \mathrm{N}_{n} \mathrm{O} \mathrm{NH}_{2}$, r.t., $92 \%$

(2) TBDPS-CI, $49 \%$

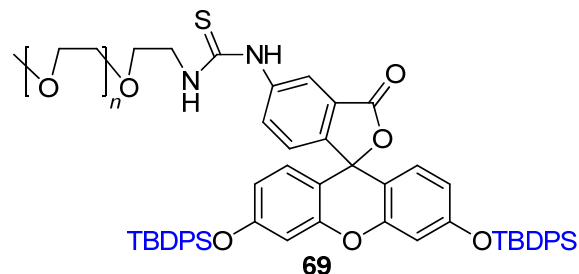

胞成像方面有所应用 ${ }^{[94]}$.

除苂光素类化合物外, 其他酚类化合物与 TBDPS$\mathrm{Cl}$ 反应, 也能成功构建氟离子荧光探针, 如最近 Venkatasubbaiah 等 ${ }^{[95]}$ 合成的 $\mathrm{F}^{-}$苂光探针 70 (Eq. 32). 在探针 70 的 DMSO 溶液中加入 $\mathrm{F}^{-}$, 其 $302 \mathrm{~nm}$ 处的紫外吸收峰 减弱, $327 \mathrm{~nm}$ 处产生新的吸收峰; 而 $392 \mathrm{~nm}$ 处的苂光发 射峰发生猝灭, $448 \mathrm{~nm}$ 处产生新的发射峰. 这是因为 $\mathrm{F}^{-}$ 的加入引起了 $\mathrm{Si}-\mathrm{O}$ 键断裂, 激活了咪唑基团上的 ESIPT 过程, 导致光谱发生变化, 故 70 能实现对 $\mathrm{F}^{-}$的检 测.<smiles>Oc1ccccc1-c1nc(-c2ccccc2)c(-c2ccccc2)[nH]1</smiles>

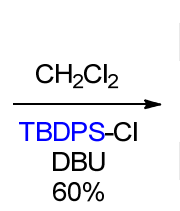<smiles>O=[Pb]c1ccccc1-c1nc(-c2ccccc2)c(-c2ccccc2)[nH]1</smiles>

当然, 也可在引入 TBDPS 基团后进一步衍生化. 例如，冯国强等 ${ }^{[96]}$ 将对羟基苯甲醛与 TBDPS-Cl 反应， 再引入氮杂环作为发色团, 由此合成了比色型 $\mathrm{F}^{-}$苂光 传感器 71 (Scheme 23), 其几分钟内就能与 $\mathrm{NaF}$ 发生响 应，检测限达 $6.6 \times 10^{-6} \mathrm{~mol} / \mathrm{L}$.

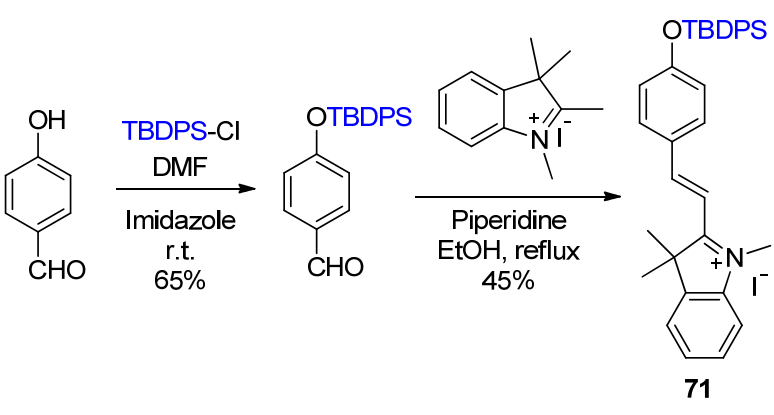

图式 23 传感器 71 的合成

Scheme 23 Synthesis of sensor $\mathbf{7 1}$
很明显，也可先衍生化后再引入 TBDPS 基团. 例 如, 汤新景等 ${ }^{[97]}$ 以化合物 48 为原料，先与三甲基乙基 氯化铵缩合，再与 TBDPS-Cl 反应，合成了苂光探针 72 (Scheme 24), 其响应时间小于 $2 \mathrm{~min}$, 检测限达 $1.4 \times$ $10^{-5} \mathrm{~mol} / \mathrm{L}$.
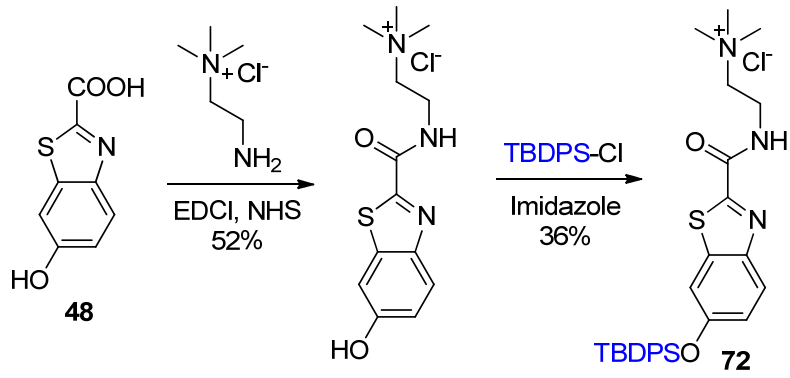

图式 24 探针 72 的合成

Scheme 24 Synthesis of probe $\mathbf{7 2}$

生物性资源水杨醛类化合物在氟离子探针合成中, 一直受到青崃. 例如，吴淑褓等 ${ }^{[98]}$ 将水杨醛衍生物 64 与 TBDPS-Cl 反应，再与 2-苯并噻唑乙腈反应，合成了 进一步成环反应型传感器 73 (Scheme 25). $F^{-}$的加入使 紫外吸收峰从 $465 \mathrm{~nm}$ 红移到 $483 \mathrm{~nm}$ 处; $521 \mathrm{~nm}$ 处产生 一个若光发射峰, 溶液颜色由黄色变为绿色. 这是由于 $\mathrm{F}^{-}$的加入, 诱导了 $\mathrm{Si}-\mathrm{O}$ 键断裂, 释放出香豆素衍生物 74, 发出绿色荣光. 基于此, 传感器 73 可实现对 $\mathrm{F}^{-}$的检 测，检测限可达 $1.45 \times 10^{-6} \mathrm{~mol} / \mathrm{L}$. 此外，其还可应用于 活细胞成像.

水杨醛衍生物 75 含有 2 个羟基, 可与 2 分子的 TBDPS-Cl 反应，进一步与罗丹明腙反应，可合成双作 用位点的 $\mathrm{F}^{-}$苂光探针 76 (Scheme 26). 在探针的 $\mathrm{CH}_{3} \mathrm{CN}$ 溶液中加入 $\mathrm{F}^{-}, 395 \mathrm{~nm}$ 处出现新的紫外吸收峰, $352 \mathrm{~nm}$ 处出现等吸收点, 裸眼可见溶液由无色变为黄色; 而其 


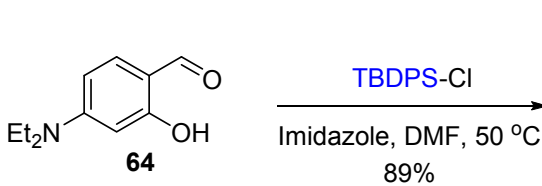<smiles>CCNc1ccc(C=O)c(O[Si](c2ccccc2)(c2ccccc2)C(C)(C)C)c1</smiles>

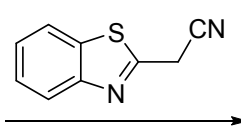

Piperidine, $\mathrm{MeOH}$ $14 \%$<smiles>CCNc1ccc(/C=C(\C#N)c2nc3ccccc3s2)c(O[Si](c2ccccc2)(c2ccccc2)C(C)(C)C)c1</smiles>

图式 25 传感器 73 的合成及其作用机理

Scheme 25 Synthesis of sensor $\mathbf{7 3}$ and its mechanism

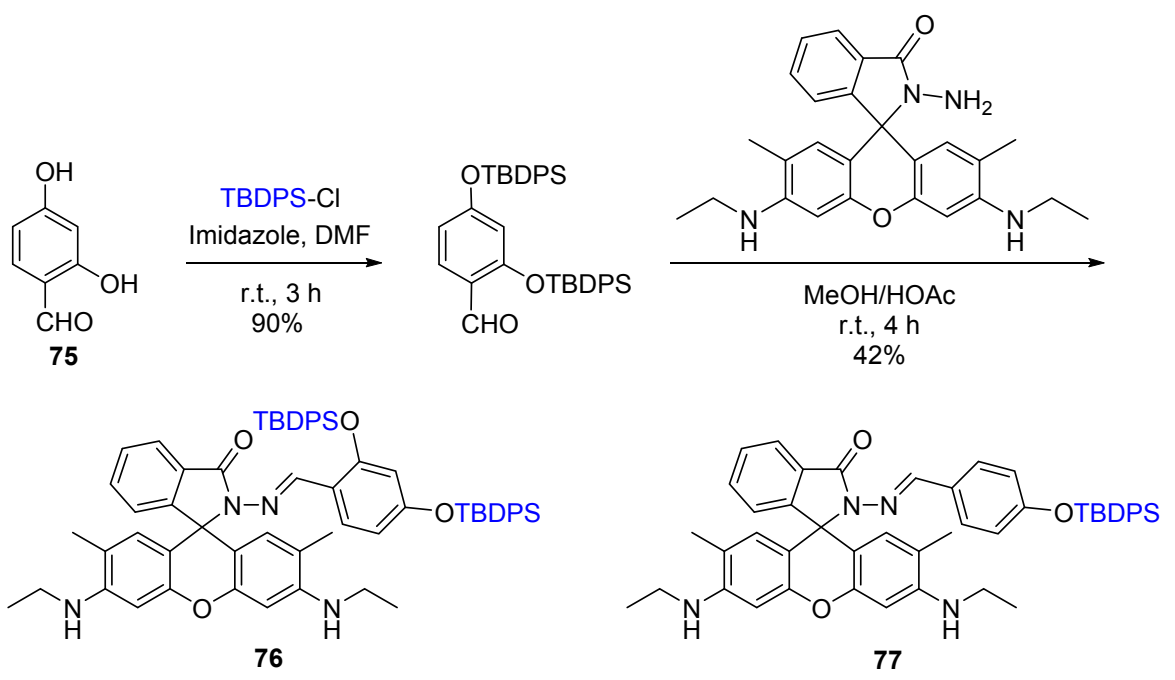

图式 26 探针 76 的合成和探针 77 的结构

Scheme 26 Synthesis of probe $\mathbf{7 6}$ and structure of probe 77

荧光发射峰由 $490 \mathrm{~nm}$ 红移到 $540 \mathrm{~nm}$ 处并显著增强. 其 他离子没有引起类似的变化, 故探针 76 可用于检测 $\mathrm{F}^{-}$. 与单作用位点的探针 77 相比, 76 的检测效果更好, 检测 限可达 $3.4 \times 10^{-9} \mathrm{~mol} / \mathrm{L}$. 此外, 探针 76 还可实现牙膏中 $\mathrm{F}^{-}$的检测 ${ }^{[99]}$.

\subsection{3 三异丙基硅基}

三异丙基硅基(TIPS)可用于保护羟基，亦可应用于 反应型氟离子探针的合成 ${ }^{[100]}$. 例如, 宁英男等 ${ }^{[101]}$ 以荎 胺为苂光团, 以 $43 \%$ 的产率合成了对 $\mathrm{F}^{-}$具有识别和选 择性检测的荧光探针 78 (Scheme 27). 向探针的二氯甲 烷溶液中加入 $\mathrm{F}^{-}, 300 \mathrm{~nm}$ 处的紫外吸收峰逐渐下降, $370 \mathrm{~nm}$ 处的吸收峰逐渐增强; 其在 $425 \mathrm{~nm}$ 处的苂光发 射峰逐渐减弱, $520 \mathrm{~nm}$ 处的荧光发射峰逐渐增强. 故该 探针能实现对 $\mathrm{F}^{-}$的检测.<smiles>C#CCNc1cccc2c(N)cccc12</smiles><smiles>O=[W]OC(=O)O</smiles><smiles>C#CCNc1cccc2c(NC(=O)Cl)cccc12</smiles><smiles>CC(C)[Si](Oc1ccc(C=O)cc1)(C(C)C)C(C)C</smiles><smiles>C#CCN[14C](=O)c1cccc2c(NC(=O)OCc3ccc(O[Si](C(C)C)(C(C)C)C(C)C)cc3)cccc12</smiles>

图式 27 探针 78 的合成

Scheme 27 Synthesis of probe $\mathbf{7 8}$ 
氟硼二吡咯类苂光染料具有较高的苂光量子产率 及较好的稳定性, 也可在氟嗍二吡咯类化合物上引入 TIPS, 合成 $\mathrm{F}^{-}$苂光探针. 例如, 邵士俊等 ${ }^{[102]}$ 将氟嗍二 吡咯类化合物 79 与 4-(三异丙基甲硅氧基)芐基溴反应, 合成 $\mathrm{F}^{-}$苂光探针 $\mathbf{8 0}$ (Scheme 28). 在 $\mathbf{8 0}$ 的磷酸盐缓冲溶 液中, 原本只在 $520 \mathrm{~nm}$ 处有一个微弱的苂光发射峰, 加 入 $\mathrm{NaF}$ 后引起 $\mathrm{Si}-\mathrm{O}$ 键断裂, 释放出绿色苂光的内消旋 一吡啶氟嗍二吡咯染料 79, 导致 $520 \mathrm{~nm}$ 处的发射峰显著 增强, 从而实现了对 $\mathrm{F}^{-}$的检测, 检测限为 $2 \times 10^{-5}$ $\mathrm{mol} / \mathrm{L}$. 此外, 探针 80 还可应用于细胞中 $\mathrm{F}^{-}$的荧光成像.

\section{2 基于与硼作用的反应型探针}

由于嗍原子有一个空的 $\mathrm{p}$ 轨道, 因此缺电子的三价 有机嗍化物极易与具有较大电负性的 $\mathrm{F}^{-}$结合. 利用 $\mathrm{F}^{-}$ 与硼原子之间的相互作用, 也能合成可用于检测 $\mathrm{F}^{-}$的 探针 ${ }^{[103]}$. 其中, 最常见的检测机理, 是将具有空 $\mathrm{p}$ 轨道 的三芳基硼烷作为路易斯酸, 通过路易斯酸-碱相互作 用, 硼原子与 $\mathrm{F}^{-}$的结合破坏了硼中心与芳香基的 $\mathrm{p}-\pi$ 共 轭, 引起三芳基硼烷光物理性质的变化, 从而实现对 $\mathrm{F}^{-}$ 的选择性检测 ${ }^{[104]}$. 例如, Jakle 等 ${ }^{[105]}$ 基于此原理合成了 高分子键接的三芳基硼烷类氟离子探针 81 (Scheme 29).
当三芳基硼烷连接有供电子芳胺基团为 $\pi$ 电子给体 时，更有利于提高探针的选择性和灵敏度 ${ }^{[104]}$, 因此可 利用此原理合成探针，如宋钦华等 ${ }^{[106]}$ 合成的基于三芳 基硼烷的 “turn-on” 型荧光探针.

类似地，王进义等 ${ }^{[107]}$ 以具有高度对称性和刚性共 轭结构的三聚茚单元作为 $\pi$ 共轭中心, 合成了 $\mathrm{F}^{-}$荧光探 针 82 (Eq. 33). 向探针 82 的 THF 溶液中加入 $\mathrm{F}^{-}, 388$ 和 $407 \mathrm{~nm}$ 处的吸收峰逐渐减弱, $365 \mathrm{~nm}$ 处的吸收峰稍稍增 强且蓝移了 $2 \mathrm{~nm}$, 裸眼可见溶液颜色由青黄色变为无 色; $530 \mathrm{~nm}$ 处的苂光发射峰发生猝灭，而 $430 \mathrm{~nm}$ 处的发 射峰强度显著增强. 这是由于 $\mathrm{F}^{-}$易与 $\mathrm{B}$ 结合, 影响了分 子的共轭结构, 导致光谱特性发生变化, 故探针 82 能实 现对 $\mathrm{F}^{-}$的检测, 检测限在 $3 \times 10^{-6}$ 到 $5 \times 10^{-6} \mathrm{~mol} / \mathrm{L}$ 之 间.

硼酸酯类有机物也能作为路易斯酸, 选择性地结合 氟离子, 嗍原子与氟离子的结合破坏了硼中心与芳香取 代基的 $\mathrm{p}-\pi$ 共轭, 引起有机嗍化合物光物理性质的变化, 从而实现对氟离子的高选择性检测 ${ }^{[108]}$, 如王利民等 ${ }^{[109]}$ 合成的吡咯并吡咯二酮类 $\mathrm{F}^{-}$苂光探针 $\mathbf{8 3}$ (Scheme 30).

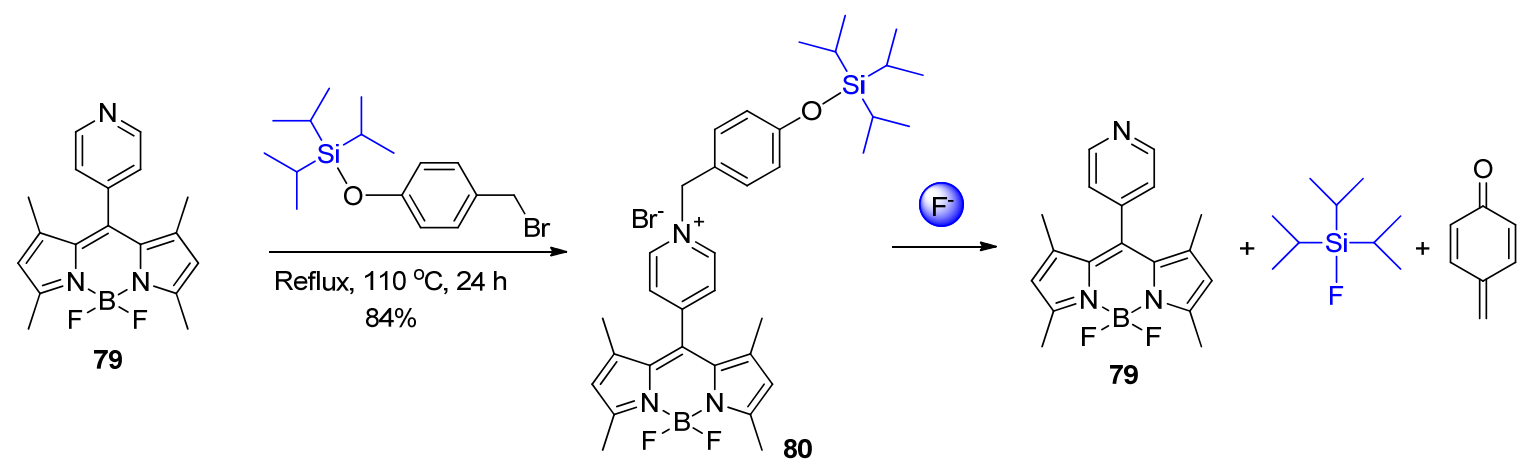

图式 28 探针 80 的合成及其作用机理

Scheme 28 Synthesis of probe $\mathbf{8 0}$ and its mechanism

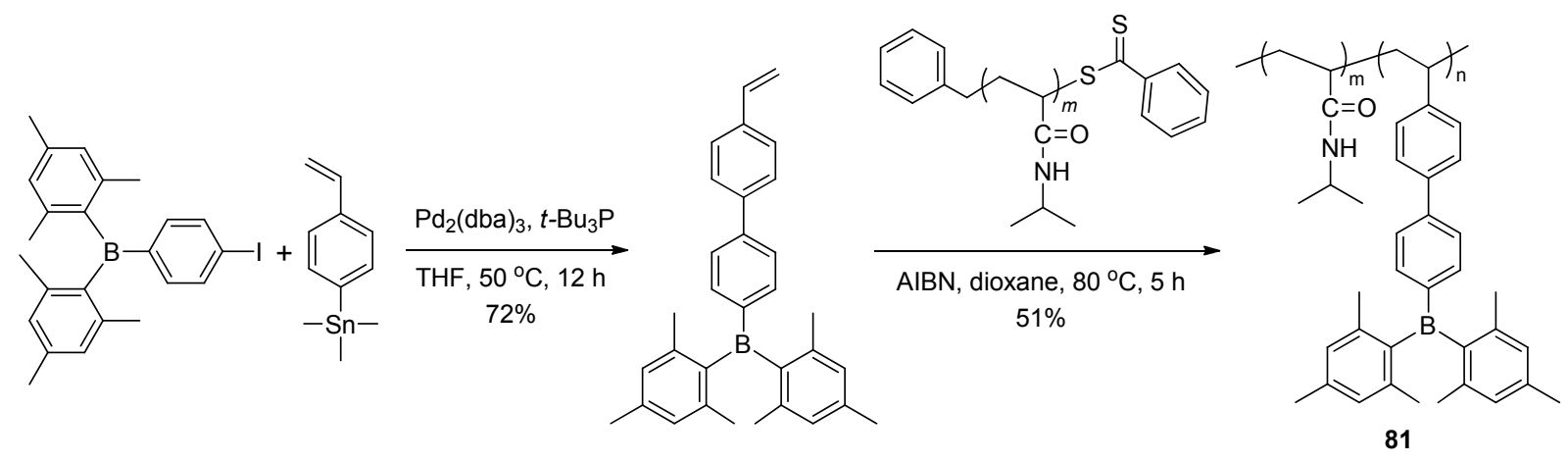

图式 29 探针 81 的合成

Scheme 29 Synthesis of probe $\mathbf{8 1}$ 

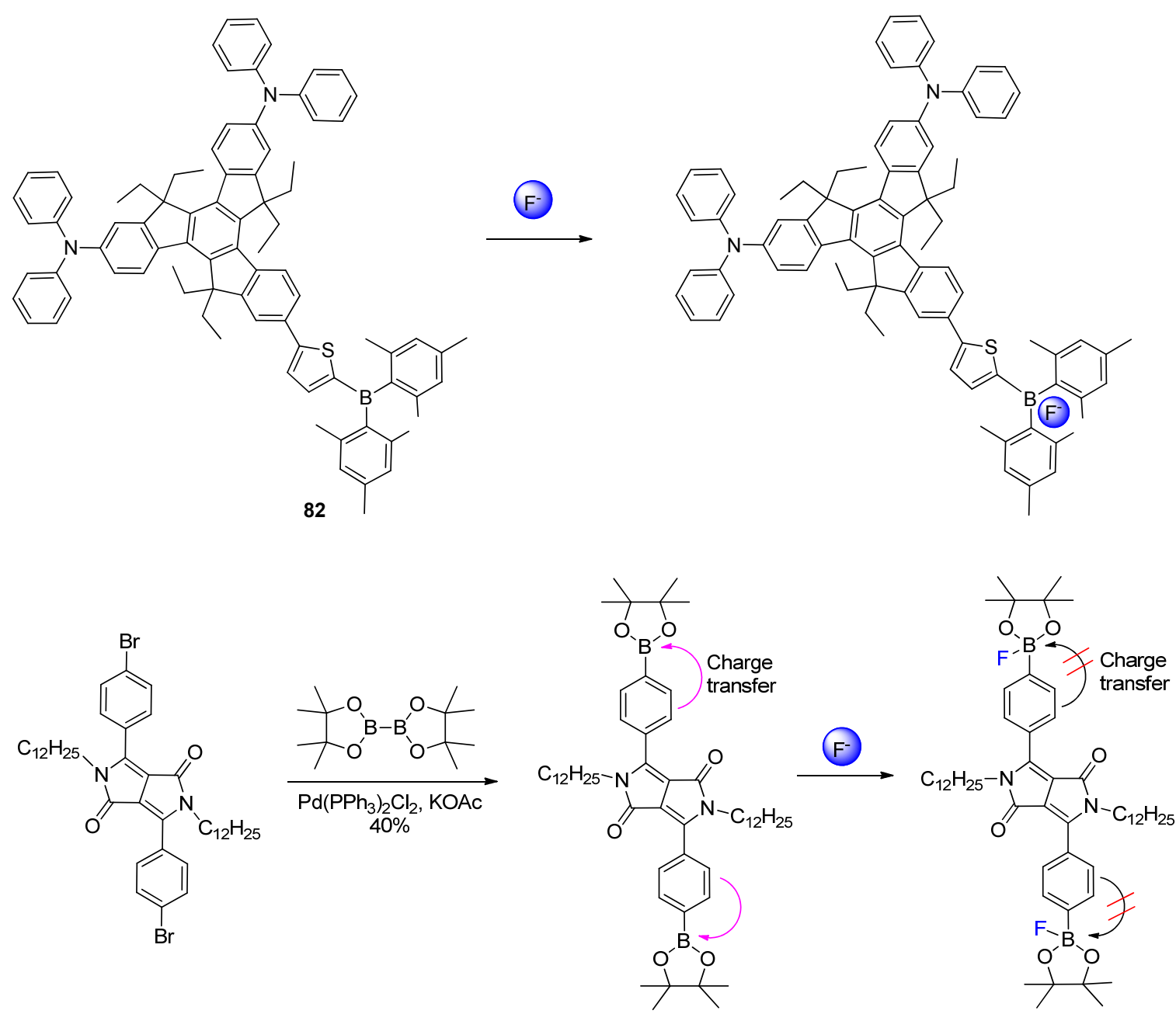

83

图式 30 探针 83 的合成及其作用机理

Scheme 30 Synthesis of probe $\mathbf{8 3}$ and its mechanism

其实, 不仅仅是含三配位嗍的有机物, 若在分子中 引入四配位的硼, 也可合成 $\mathrm{F}^{-}$荧光探针 ${ }^{[110]}$. 例如, 汪 凌云等 ${ }^{[111]}$ 先合成了氟嗍二吡咯类化合物 84, 再通过聚 合反应合成了氟硼二吡咯类 $\mathrm{F}^{-}$探针 85 (Scheme 31). 向 探针 85 的 $\mathrm{THF} / \mathrm{H}_{2} \mathrm{O}(V: V=98: 2)$ 溶液中加入 $\mathrm{F}^{-}, 594$ $\mathrm{nm}$ 处的紫外吸收峰减弱, $488 \mathrm{~nm}$ 处产生一个新的吸收 峰, 裸眼可见溶液颜色由紫色变成橙色; $648 \mathrm{~nm}$ 处的苂 光发射峰猝灭, $579 \mathrm{~nm}$ 处的发射峰增强. 这是由于 $\mathrm{F}^{-}$易 与中心 B 络合, 进一步使 B- $\mathrm{N}$ 键断裂, 探针的结构发 生改变, 光谱性质也随之而变, 从而实现对 $\mathrm{F}^{-}$的检测, 检测限达 $5.23 \times 10^{-7} \mathrm{~mol} / \mathrm{L}$. 此外, 该探针还可用于细胞 成像.

除了上面所提到的含三配位硼和四配位嗍的 $\mathrm{F}^{-}$荧 光探针外, 近年来也有研究者同时引入三芳基硼和氟硼 二吡咯而合成苂光探针. 例如, Misra 等 ${ }^{[112]}$ 利用芳基喼 化合物和 8-氯氟嗍二吡咯化合物合成探针 86 (Eq. 34). 在探针 86 的 THF 溶液中加入 $\mathrm{F}^{-}, \mathrm{F}^{-}$会先与三芳基嗍上
的 B 进行配位，导致其荧光慢慢减弱, $566 \mathrm{~nm}$ 处的苂光 发射峰发生猝灭; 其在 300 430 nm 的紫外吸收峰逐渐 减弱, $547 \mathrm{~nm}$ 处的吸收峰蓝移到 $532 \mathrm{~nm}$ 处且吸收强度 逐渐增强, 溶液颜色由橙色变为粉色. 当 $\mathrm{F}^{-}$的加入量大 于 1 equiv. 后, 过量的 $\mathrm{F}^{-}$继续进攻氟硼二吡咯核上的 $\mathrm{B}$, 与其进行配位, 使探针在 $532 \mathrm{~nm}$ 处的紫外吸收峰开始 减弱; 而荧光则继续减弱, 直至 2 当量时完全猝灭. 基 于以上光谱变化, 探针 86 能实现对 $\mathrm{F}^{-}$的检测.

最近, 汪凌云等 ${ }^{[113]}$ 在氟硼二吡咯类化合物 84 上引 入两个 3,5-二甲氧基苯基以增强共轭，再引入缺电子的 频哪醇嗍酸盐基团以提高探针对 $\mathrm{F}^{-}$的选择性，合成了 $\mathrm{F}^{-}$苂光探针 87 (Scheme 32). 在探针 87 的 THF/ $\mathrm{H}_{2} \mathrm{O}(V$ : $V=98: 2$ ) 溶液中加入 $\mathrm{F}^{-}, 560 \mathrm{~nm}$ 处的紫外吸收峰减弱, $620 \mathrm{~nm}$ 处产生新的吸收峰, 溶液颜色由玫红色变为靛 蓝色; 而其苂光发射峰从 $599 \mathrm{~nm}$ 处蓝移到 $579 \mathrm{~nm}$ 处, 493 和 $639 \mathrm{~nm}$ 处产生新的发射峰. 这是因为加入 $F^{-}$之 后, $\mathrm{F}^{-}$能与频哪醇硼酸盐结合, 同时引起氟㸴二吡咯基 


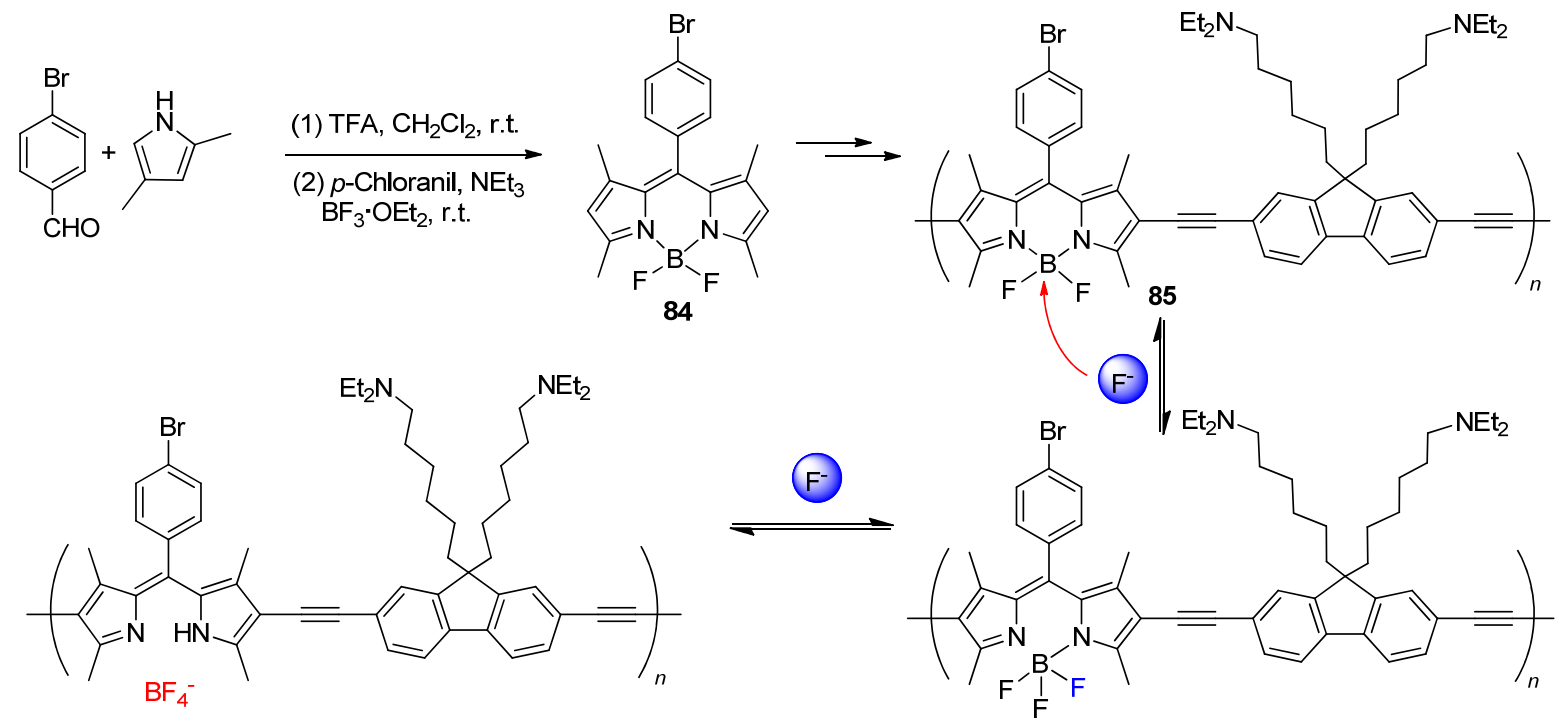

图式 31 探针 85 的合成及其作用机理

Scheme 31 Synthesis of probe $\mathbf{8 5}$ and its mechanism
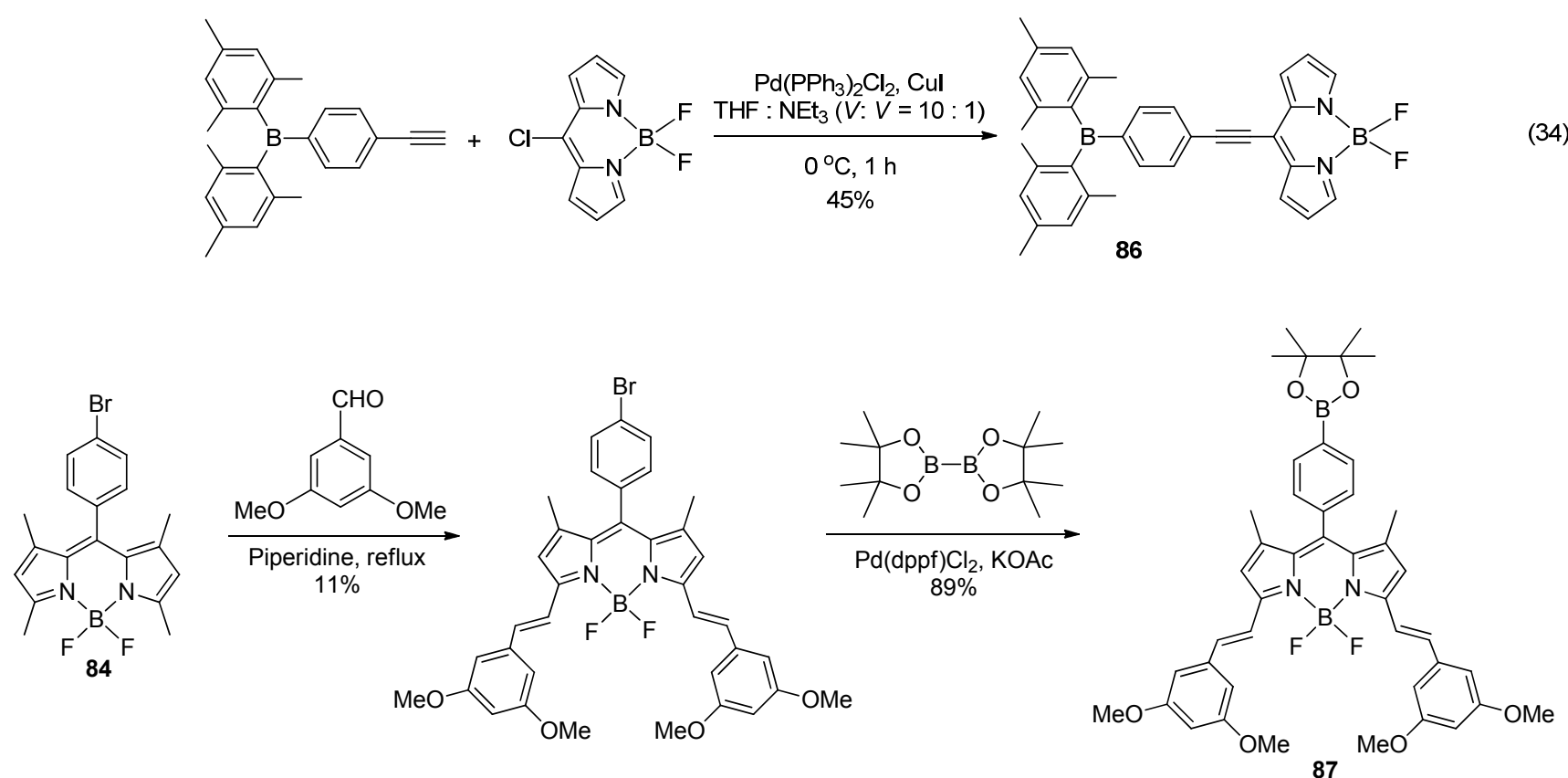

图式 32 探针 87 的合成

Scheme 32 Synthesis of probe 87

团的裂解, 导致光谱发生改变. 因此, 探针 87 能实现对 $\mathrm{F}^{-}$的检测, 检测限达 $5.23 \times 10^{-7} \mathrm{~mol} / \mathrm{L}$.

\section{3 基于与金属作用的反应型探针}

近年来, 基于与金属作用的氟离子探针也开始引起 关注 ${ }^{[114,115]}$, 它们经常利用金属离子分别与探针、 $\mathrm{F}^{-}$的不 同络合作用而引起的荧光变化, 实现对 $\mathrm{F}^{-}$的选择性识 别 ${ }^{[116]}$. 特别是具有连续识别功能的荧光探针, 近年来 更是备受关注. 其中, 最常见的是 $\mathrm{Fe}^{3+}$ 与苂光探针络合, 再原位与 $\mathrm{F}^{-}$作用, 产生 “on-off-on” 或 “off-on-off” 的
苂光效应. 例如, Bhalla 等 ${ }^{[117]}$ 利用三唑类化合物与四溴 并五苯醌反应合成探针 88 (Scheme 33). 向探针的 $\mathrm{THF} / \mathrm{H}_{2} \mathrm{O}(V / V=9.5 / 0.5)$ 溶液中加入 $\mathrm{Fe}^{3+}$, 探针 88 与 $\mathrm{Fe}^{3+}$ 络合, 其 $542 \mathrm{~nm}$ 处的苂光发射峰逐渐减弱, 继续向 探针和 $\mathrm{Fe}^{3+}$ 的络合物溶液中加入 $\mathrm{F}^{-}$, 则在 $\mathrm{F}^{-}$的作用下, 苂光恢复. 因此，探针 88 能够以 “on-off-on” 的苂光效 应实现对 $\mathrm{Fe}^{3+}$ 和 $\mathrm{F}^{-}$的连续识别, 对 $\mathrm{F}^{-}$的检测限可达 $4 \times 10^{-6} \mathrm{~mol} / \mathrm{L}$. 


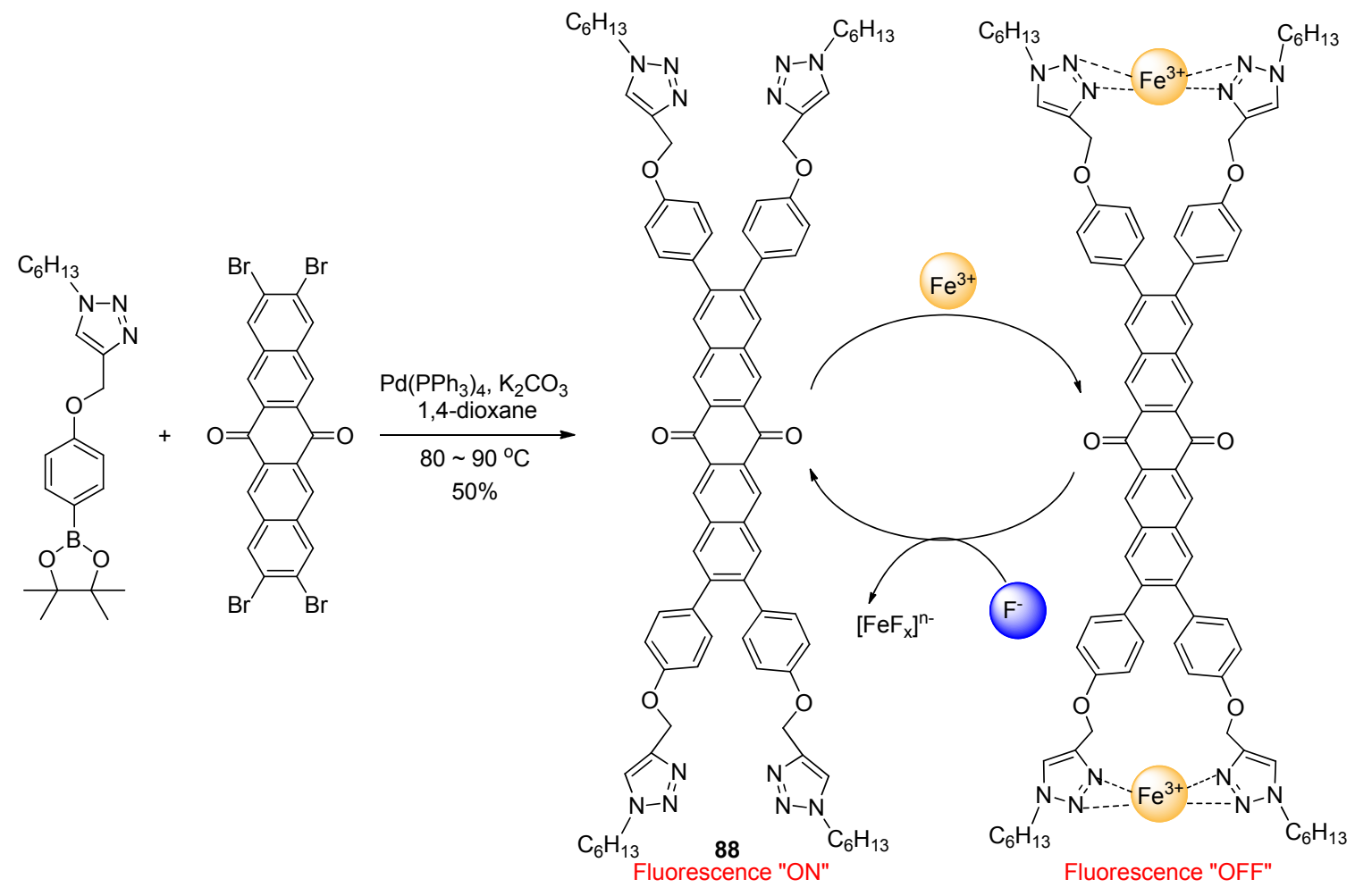

图式 33 探针 88 的合成及其作用机理

Scheme 33 Synthesis of probe $\mathbf{8 8}$ and its mechanism

魏太保等 ${ }^{[118]}$ 利用邻苯二胺和草酸在 PPA 作用下反 应生成联二苯并咪唑中间体, 然后与丙烯酸甲酯反应, 最后进行水解, 以 $87 \%$ 的总产率得到化学传感器 89 (Scheme 34). 在 $\mathrm{H}_{2} \mathrm{O} / \mathrm{DMSO}\left(V: V=4: 6\right.$ ) 溶液中, $\mathrm{Fe}^{3+}$ 通过羰基 $\mathrm{O}$ 和咪唑 $\mathrm{N}$ 与络合物以 $1: 1$ 的形式络合, 苂 光发生猝灭. 在该溶液中继续加入 $\mathrm{F}^{-}$后, 其与 $\mathrm{Fe}^{3+}$ 络 合, 使 $\mathrm{Fe}^{3+}$ 从原络合物中解离出来, 导致其苂光恢复. 而其他阴离子则几乎没有影响. 因此, 该设计能成功地 得到用于连续检测 $\mathrm{Fe}^{3+}$ 和 $\mathrm{F}^{-}$的“on-off-on” 型传感器, 对 $\mathrm{F}^{-}$的检测限可达 $1.0 \times 10^{-9} \mathrm{~mol} / \mathrm{L}$.
Ramesh 等 ${ }^{[119]}$ 以喹啉-2-甲醛和 2-氨基苯并咪唑为 原料合成苂光探针 90 (Scheme 35). 在探针的 $\mathrm{CH}_{3} \mathrm{CN} /$ $\operatorname{HEPES}(V: V=1: 4)$ 溶液中加入 $\mathrm{Fe}^{3+}, \mathrm{Fe}^{3+}$ 以 $1: 1$ 与探 针络合, $472 \mathrm{~nm}$ 处的苂光发射峰红移至 $478 \mathrm{~nm}$ 处并逐 渐增强. 继续向该溶液中加入 $\mathrm{F}^{-}, \mathrm{Fe}^{3+}$ 从原络合物中解 离出来而生成新的络合物, 使探针恢复为原来的结构, 则苂光又开始减弱. 基于这种 “off-on-off” 的苂光变 化, 探针可实现 $\mathrm{Fe}^{3+}$ 和 $\mathrm{F}^{-}$的连续识别. 此外, 探针 90 $-\mathrm{Fe}^{3+}$ 复合体还可用于对 HeLa 细胞等体内 $\mathrm{F}^{-}$的检测.<smiles>Nc1ccccc1[NH2+]C(=O)C(=O)O</smiles>

(1) $\mathrm{H}_{2} \mathrm{C}=\mathrm{CHCOOCH}_{3}$ $\mathrm{K}_{2} \mathrm{CO}_{3}, \mathrm{DMF}, 90^{\circ} \mathrm{C}$

(2) $40 \% \mathrm{NaOH}, \mathrm{EtOH}, 95^{\circ} \mathrm{C}$

图式 34 传感器 89 的合成

Scheme 34 Synthesis of sensor 89<smiles>O=Cc1ccc2ccccc2n1</smiles><smiles></smiles><smiles>FC(F)(F)C(Cc1cccc2[nH]c(/N=C/c3ccc4ccccc4n3)nc12)C(F)(F)F</smiles><smiles></smiles>

图式 35 探针 90 的合成及其作用机理

Scheme 35 Synthesis of probe $\mathbf{9 0}$ and its mechanism 
$\mathrm{Al}^{3+}$ 也可应用于 “ off-on-off” 型的传感器而识别 $\mathrm{F}^{-}$, 如 Bharadwaj 等 ${ }^{[120]}$ 合成的罗丹明类传感器能实现对 $\mathrm{Al}^{3+}$ 和 $\mathrm{F}^{-}$的连续识别. 最近, Chattopadhyay 等 ${ }^{[121]}$ 以罗 丹明 $\mathrm{B}$ 为原料, 合成了可用于检测 $\mathrm{Al}^{3+}$ 的化合物 91 , 再 将 91 与 $\mathrm{Al}\left(\mathrm{NO}_{3}\right)_{3} \bullet 9 \mathrm{H}_{2} \mathrm{O}$ 反应, 形成的螯合物即可作为 $\mathrm{F}$ - 检测苂光探针 92 (Scheme 36). 向 $\mathrm{Al}^{3+}$ 络合物探针的 HEPES 缓冲溶液(含 $25 \% \mathrm{EtOH}$ ) 中加入 $\mathrm{F}^{-}, 590 \mathrm{~nm}$ 处的 荧光发射峰发生猝灭, 这是由于在 $\mathrm{F}^{-}$的作用下, 络合物 解离, 重新得到化合物 91, 导致荧光发生改变. 其他阴 离子几乎没有影响, 故探针 92 能实现对 $\mathrm{F}^{-}$的识别. 此 外, 探针 92 还可用于细胞成像.

类似的, 利用 $\mathrm{Cu}^{2+}$ 与 $\mathrm{F}^{-}$之间的作用, 也可合成荧光 探针. 例如, Misra 等 ${ }^{[122]}$ 利用水杨酫和乙酰乙酸乙酯缩 合得到 $\alpha$-吡喃酮化合物, 再与溴反应得到澳乙酰基香豆 素, 随后与硫脲类化合物反应, 最后将所得的氨基噻唑 香豆素与水杨醛反应, 合成了苂光探针 93 (Scheme 37). 向探针 93 的 $\mathrm{CH}_{3} \mathrm{CN}$ 溶液中加入 $\mathrm{Cu}^{2+}, \mathrm{Cu}^{2+}$ 能与探针以 $1: 1$ 络合, 导致其 $520 \mathrm{~nm}$ 处的苂光发射峰发生猝灭, 继续向该溶液中加入 $\mathrm{F}^{-}$, 苂光又逐渐恢复. 这是由于在 $\mathrm{F}^{-}$作用下, $\mathrm{Cu}^{2+}$ 从络合物中解离出来, 菼光恢复. 因此,
探针 93 能通过 “on-off-on” 的苂光效应实现对 $\mathrm{Cu}^{2+}$ 和 $\mathrm{F}^{-}$的连续检测, 其对 $\mathrm{F}^{-}$的检测限为 $8.1 \times 10^{-9} \mathrm{~mol} / \mathrm{L}$.

\section{4 基于其他作用的反应型探针}

三甲基硅基是末端炔的常见保护基团之一，其在 $\mathrm{F}^{-}$的作用下能被脱除, 利用这种性质也可设计合成 $\mathrm{F}^{-}$ 苂光探针. 例如, Choi 等 ${ }^{[123]}$ 在吡咯并吡咯二酮类化合物 上引入两个三甲基硅基，合成 $\mathrm{F}^{-}$苂光探针 94 (Eq. 35). 在探针 94 的 THF-HEPES 缓冲液 $(V: V=8: 2, \mathrm{pH}$ 7.4) 中加入 $\mathrm{F}^{-}$, 其在 $319 \mathrm{~nm}$ 处的紫外吸收峰逐渐增强, 385、 $408 、 549 、 589 \mathrm{~nm}$ 处的吸收峰减弱; 而荧光发射峰从 617 $\mathrm{nm}$ 蓝移到了 $604 \mathrm{~nm}$ 处. 这是由于在 $\mathrm{F}^{-}$的作用下, $\mathrm{Si}-\mathrm{C}$ 键断裂, 三甲基硅基脱去, 导致光谱发生变化. 因此, 探针 94 能实现对 $\mathrm{F}^{-}$的检测, 检测限达 $2 \times 10^{-7} \mathrm{~mol} / \mathrm{L}$.

在国内, 刘睿等 ${ }^{[124]}$ 合成了包含有两个三甲基硅乙 炔基的多环芳烃苂光探针 95 (Scheme 38). 在探针 95 的 THF 溶液中加入 $\mathrm{F}^{-}$, 紫外吸收峰蓝移, 裸眼可见溶液颜 色由黄色变为无色; $447 \mathrm{~nm}$ 处的苂光发射峰减弱, 427 $\mathrm{nm}$ 处出现新的发射峰, 紫外灯下溶液颜色由蓝绿色变 为蓝色. 因此, 探针 95 可实现对 $\mathrm{F}^{-}$的检测, 检测限达 $4.8 \times 10^{-8} \mathrm{~mol} / \mathrm{L}$.

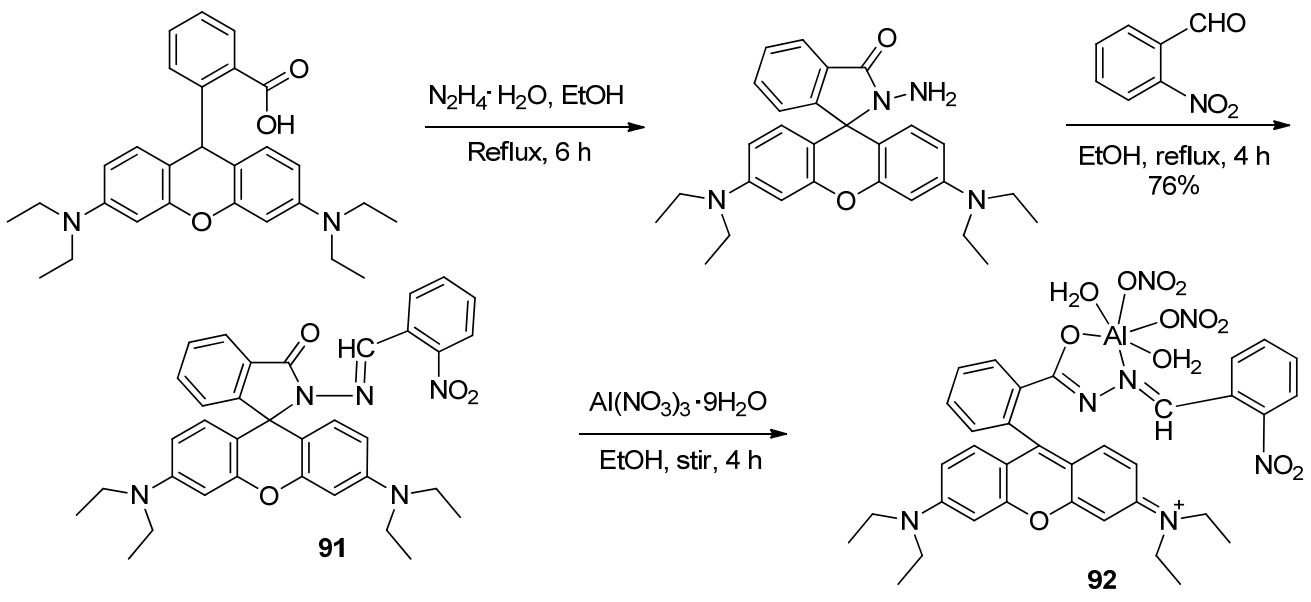

图式 36 探针 92 的合成

Scheme 36 Synthesis of probe 92
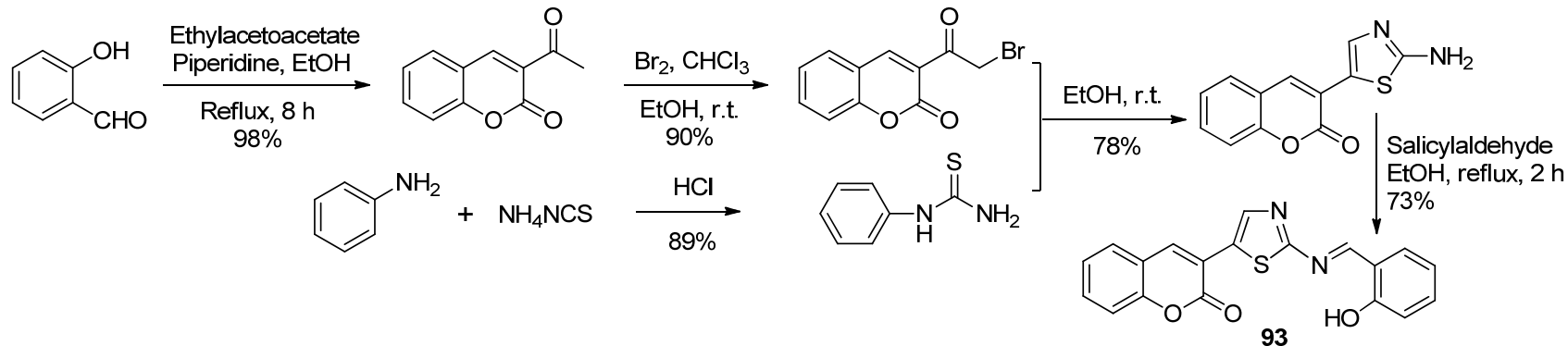

图式 37 探针 93 的合成 Scheme 37 Synthesis of probe $\mathbf{9 3}$ 


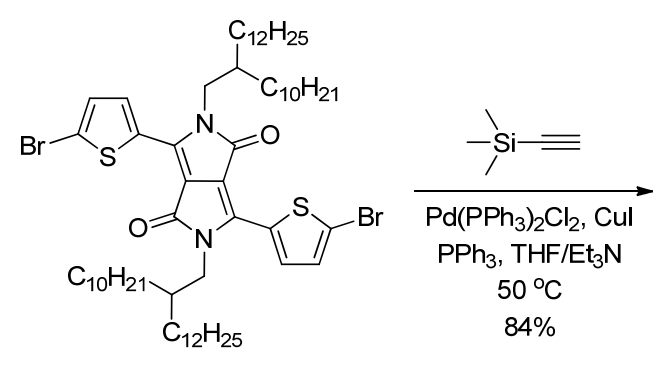

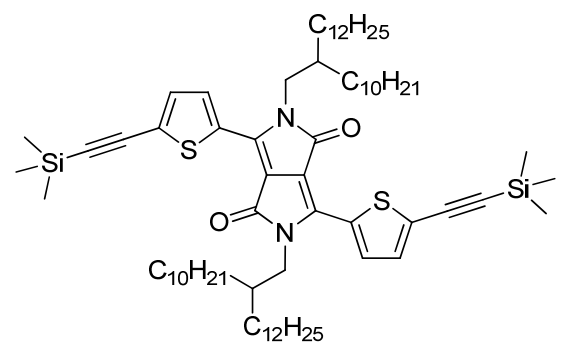<smiles>Nc1c(Br)ccc(Br)c1N</smiles>

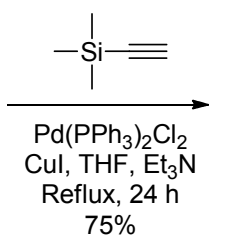<smiles>C[Si](C)(C)C#Cc1ccc(C#C[Si](C)(C)C)c(N)c1N</smiles>

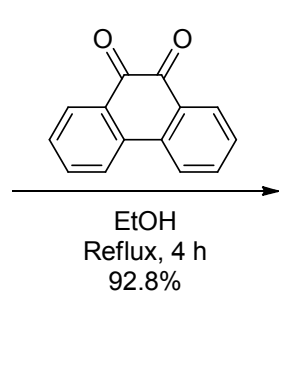<smiles>C[Si](C)(C)C#Cc1ccc(C#C[Si](C)(C)C)c2nc3c4ccccc4c4ccccc4c3nc12</smiles>

图式 38 探针 95 的合成

Scheme 38 Synthesis of probe 95

除了上面提到的几种外, 近年来其他类型的 $\mathrm{F}^{-}$荧

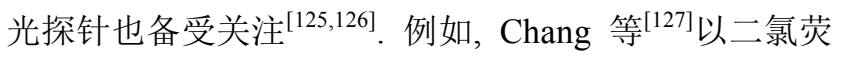
光素和二甲基硫代磷酰氯为原料, 合成基于 $\mathrm{P}-\mathrm{O}$ 键断 裂的 $\mathrm{F}^{-}$苂光探针 96 (Scheme 39). 在 $\mathrm{DMSO} /$ 氨丁三醇 $(V: V=7: 3)$ 溶液中, 探针 96 原本没有明显的紫外吸 收峰, $\mathrm{F}^{-}$的加入使 $516 \mathrm{~nm}$ 处出现一个强吸收峰, 溶液颜 色由无色变为黄绿色; 而原本极其微弱的苂光, 也由于 $\mathrm{F}^{-}$的加入而变强, $536 \mathrm{~nm}$ 处的发射峰显著增强. 这是由 于在 $\mathrm{F}^{-}$的作用下, 探针分子水解, 产生有较高苂光量子<smiles>O=C1OC2(c3cc(Cl)c(O)cc3Oc3cc(O)c(Cl)cc32)c2ccccc21</smiles>

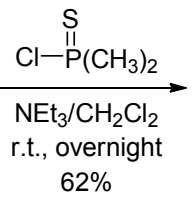<smiles>CP(C)(=S)Oc1cc2c(cc1Cl)C1(OC(=O)c3cc(OP(C)(C)=S)c(Cl)cc31)c1ccccc1O2</smiles><smiles>CP(C)(O)=S</smiles>

图式 39 探针 96 的合成及其作用机理 Scheme 39 Synthesis of probe 96 and its mechanism
产率的醌型二氯苂光素 97, 使荧光信号增强. 其他阴离 子基本没有引起变化, 故该成功的设计可用于 $\mathrm{F}^{-}$的检 测, 检测限达 $9.8 \times 10^{-9} \mathrm{~mol} / \mathrm{L}$.

\section{3 结束语}

关于氟离子荧光探针的研究, 无论是去质子化型还 是反应型, 近年来发展都十分迅速, 它们涉及到了 PET、ICT、ESIPT 等不同的荧光检测机制, 所用的合 成原料与反应类型也五花八门. 但是, 从绿色化学的角 度看, 目前利用易得原料与绿色反应的报道仍然有限. 同时，现在许多氟离子荧光探针的设计目标，往往只是 局限于追求氟离子检测的高灵敏性与选择性.

实际上，氟离子的检测本身是绿色化学中 “在线检 测” 的一部分 ${ }^{[128]}$. 因此, 在开发检测灵敏度高、选择 性好的氟离子探针过程中 ${ }^{[129]}$, 进一步利用生物性资源

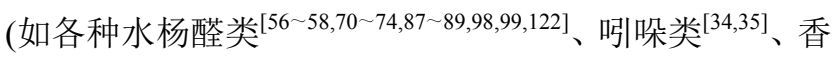
豆素类 ${ }^{[66]}$ 化合物和氨基己糖 ${ }^{[00]}$ 等), 以各种原子经济性 反应与绿色化学技术手段 ${ }^{[130]}$ 进行合成, 并加强在生物 体内与水相介质中的应用研究, 从而全面实现氟离子苂 光探针研究的绿色化, 这很有必要, 也是氟离子荧光探 针未来的发展方向.

\section{References}

[1] Kaur, K.; Mittal, S. K.; Kumar, S. K. A.; Kumar, A.; Kumar, S Anal. Methods 2013, 5, 5565.

[2] Brugnara, A.; Topic, F.; Rissanen, K.; de La Lande, A.; Colasson, B.; Reinaud, O. Chem. Sci. 2014, 5, 3897. 
[3] Langton, M. J.; Serpell, C. J.; Beer, P. D. Angew. Chem., Int. Ed. 2015, 55, 1974.

[4] Wu, S.-Z.; Han, T.-Y.; Guo, J.-J.; Cheng, Y.-S. Sens. Actuators, B 2015, 220, 1305.

[5] Mani, V.; Li, W.-Y.; Gu, J.-A.; Lin, C.-M.; Huang, S.-T. Talanta 2015, 131, 121.

[6] Cametti, M; Rissanen, K. Chem. Commun. 2009, 2809.

[7] Cametti, M.; Rissanen, K. Chem. Soc. Rev. 2013, 42, 2016.

[8] Manjare, S. T; Kim, Y; Churchill, D. G. Acc. Chem. Res. 2014, 47, 2985.

[9] Zhou, Y.; Zhang, J. F.; Yoon, J. Chem. Rev. 2014, 114, 5511.

[10] Jiao, Y.; Zhu, B.-C.; Chen, J.-H.; Duan, X.-H. Theranostics 2015, 5, 173.

[11] Zhen, W.; Ying, Z.; Jun, R. Chem. Sens. 2012, 32, 41 (in Chinese). (吴振, 周应, 任君, 化学传感器, 2012, 32, 41.)

[12] Li, Y.-J.; Xie, D.-Y.; Pang, X.-L.; Yu, X.-D.; Yu, T.; Ge, X.-T. Sens. Actuators, B 2016, 227, 660.

[13] Sun, J.-Q.; Ye, B.-F.; Xia, G.-M.; Zhang, X.-H.; Wang, H.-M. Sens. Actuators, B 2016, 233, 76.

[14] Bhoi, A. K.; Das, S. K.; Majhi, D.; Sahu, P. K.; Nijamudheen, A.; Anoop, N.; Rahaman, A.; Sarkar, M. J. Phys. Chem. B 2014, 118, 9926.

[15] Hu, J.-M.; Li, C.-H.; Cui, Y.; Liu, S.-Y. Macromol. Rapid Commun. 2011, 32, 610 .

[16] Saravanan, C.; Easwaramoorthi, S.; Hsiow, C. Y.; Wang, K.; Hayashi, M.; Wang, L. Org. Lett. 2014, 16, 354.

[17] Sivaraman, G.; Chellappa, D. J. Mater. Chem. B 2013, 1, 5768.

[18] Wu, Y.-C.; You, J.-Y.; Guan, L.-T. Shi, J.; Cao, L.; Wang, Z.-Y. Chin. J. Org. Chem. 2015, 35, 2465 (in Chinese). (吴彦城, 尤嘉宜, 关丽涛, 石杰, 曹梁, 汪朝阳, 有机化学, 2015, 35, 2465.)

[19] Batista, R. M. F.; Costa, S. P. G.; Raposo, M. M. M. J. Photochem. Photobiol. A 2013, 259, 33.

[20] Ali, R.; Razi, S. S.; Gupta, R. C.; Dwivedi, S. K.; Misra, A. New J. Chem. 2016, 40, 162.

[21] Hu, J.-Y.; Liu, R.; Zhu, X.-L.; Cai, X.; Zhu, H.-J. Chin. Chem. Lett. 2015, 26, 339.

[22] Xiong, J.; Cui, L.; Liu, W.; Beves, J. E.; Li, Y.-Y.; Zuo, J.-L. Tetrahedron Lett. 2013, 54, 1998.

[23] Yang, C.-L.; Xu, J.; Li, J.-Y.; Lu, M.-G.; Li, Y.-B.; Wang, X.-L. Sens. Actuators, B 2014, 196, 133.

[24] Liu, T.; Nonat, A.; Beyler, M.; Regueiro-Figueroa, M.; Nono, K. N.; Jeannin, O.; Camerel, F.; Debaene, F.; Cianferani-Sanglier, S.; Tripier, R. Angew. Chem., Int. Ed. 2014, 53, 7259.

[25] Sarkar, A.; Bhattacharyya, S.; Mukherjee, A. Dalton Trans. 2016, 45, 1166.

[26] Parthiban, C.; Ciattini, S.; Chelazzi, L.; Elango, K. P. Sens. Actuators, B 2016, 231, 768 .

[27] Parthiban, C.; Elango, K. P. Sens. Actuators, B 2015, 215, 544.

[28] Pazik, A.; Skwierawska, A. Supramol. Chem. 2013, 25, 189.

[29] Yang, X.-F.; Zhang, G.-G.; Li, Y.-X.; Liu, Z.; Gong, X.-Q.; Gao, B.; Zhang, G.-Y.; Cui, Y.; Sun, G.-X. RSC Adv. 2015, 5, 22455.

[30] Uahengo, V.; Xiong, B.; Cai. P.; Daniel, L. S. Rhyman, L.; Ramasami, P. Anal. Chem. Res. 2016, 8,1 .

[31] Yang, X.-F.; Xie, L.-J.; Ning, R.; Gong, X.-Q.; Liu, Z.; Li, Y.-X.; Zheng, L.-Y.; Zhang, G.-G.; Gao, B.; Cui, Y.; Sun, G.-X.; Zhang, G.-Y. Sens. Actuators, B 2015, 210, 784.

[32] Niu, H.; Shu, Q.-H.; Jin, S.-H.; Li, B.-J.; Zhu, J.-P.; Li, L.-J.; Chen, S.-S. Spectrochim. Acta, Part A 2016, 153, 194.

[33] Chetia, B.; Iyer, P. K. Sens. Actuators, B 2014, 201, 191.

[34] Liu, X.-M.; Zhao, Q.; Li, Y.; Song, W.-C.; Li, Y.-P.; Chang, Z.; Bu, X.-H. Chin. Chem. Lett. 2013, 24, 962.
[35] Jeyanthi, D.; Iniya, M.; Krishnaveni, K.; Chellappa, D. Spectrochim. Acta, Part A 2015, 136, 1269.

[36] Anand, T.; Sivaramana, G.; Iniya, M.; Siva, A.; Chellappa, D. Anal. Chim. Acta 2015, 876, 1.

[37] Lee, J. Y.; Rao, B. A.; Hwang, J. Y.; Son, Y. A. Sens. Actuators, B 2015, 220, 1070.

[38] Vinithra, G.; Suganya, S.; Velmathi, S. Tetrahedron Lett. 2013, 54, 5612.

[39] Satheshkumar, A.; Elango, K. P. Dyes Pigm. 2013, 96, 364.

[40] Kumar, S. M.; Dhahagani, K.; Rajesh, J. Nehru, K.; Annaraj, J.; Chakkaravarthi, G.; Rajagopal, G. Polyhedron 2013, 59, 58.

[41] Ashokkumar, P.; Weisshoff, H.; Kraus, W.; Rurack, K. Angew. Chem., Int. Ed. 2014, 53, 2225.

[42] Yan, X.-Q.; Zhuo, J.-B.; Wang, J.-C.; Yuan, Y.-F. Chin. J. Org. Chem. 2015, 35, 2184 (in Chinese).

(晏希泉, 卓继斌, 王吉成, 谢莉莉, 袁耀锋, 有机化学, 2015, 35, 2184.)

[43] Basheer, S. M.; Willis, A. C.; Pace, R. J.; Sreekanth, A. Polyhedron 2016, 109, 7 .

[44] Sharma, S.; Hundal, M. S.; Hundal, G. Tetrahedron Lett. 2013, 54, 2423.

[45] Yang, X.-F.; Zheng, L.-Y.; Xie, L.-J.; Liu, Z.; Li, Y.-X.; Ning, R.; Zhang, G.-G.; Gong, X.-Q.; Gao, B.; Liu, C.-X.; Cui, Y.; Sun, G.-X.; Zhang, G.-Y. Sens. Actuators, B 2015, 207, 9.

[46] Mahapatra, A. K.; Karmakar, P.; Roy, J.; Manna, S.; Maiti, K.; Sahoo, P.; Mandal, D. RSC Adv. 2015, 5, 37935.

[47] Biswas, S.; Gangopadhyay, M.; Barman, S.; Sarkar, J.; Singh, N. D. P. Sens. Actuators, B 2016, 222, 823.

[48] Liu, Y.-W.; Kao, M.-X.; Wu, A.-T. Sens. Actuators, B 2015, 208, 429.

[49] Goswami, S.; Maity, S.; Maity, A. C.; Das, A. K.; Pakhira, B.; Khanra, K.; Bhattacharyya, N.; Sarkar, S. RSC Adv. 2015, 5, 5735.

[50] Singh, J.; Yadav, M.; Singh, A.; Singh, N. Dalton Trans. 2015, 44, 12589.

[51] Mori, H.; Takahashi, E.; Ishizuki, A.; Nakabayashi, K. Macromolecules 2013, 46, 6451

[52] Erdemir, S.; Kocyigit, O.; Alici, O.; Malkondu, S. Tetrahedron Lett. 2013, 54, 613 .

[53] Sharma, R.; Mittal, S. K.; Chhibber, M. J. Electrochem. Soc. 2015, $162, \mathrm{~B} 248$.

[54] Maiti, D. K.; Roy, S.; Datta, A.; Banerjee, A. Chem. Phys. Lett. 2013, 588,76 .

[55] Khanmohammadi, H.; Rezaeian, K. RSC Adv. 2014, 4, 1032.

[56] Alam, P.; Kachwal, V.; Laskar, I. R. Sens. Actuators, B 2016, 228, 539.

[57] Suganya, S.; Velmathi, S. J. Mol. Recognit. 2013, 26, 259.

[58] Na, Y. J.; Choi, Y. W.; Yun, J. Y.; Park, K. M.; Chang, P. S.; Kim, C. Spectrochim. Acta, Part A 2015, 136, 1649.

[59] Song, E. J.; Kim, H.; Hwang, I. H.; Kim, K. B.; Kim, A. R.; Noh, I.; Kim, C. Sens. Actuators, B 2014, 195, 36.

[60] Lin, Q.; Yang, Q.-P.; Sun, B.; Lou, J.-C.; Wei, T.-B.; Zhang, Y.-M. RSC Adv. 2015, 5, 11786 .

[61] Yan, G.-T.; Wu, G.-Y. ; Qu, W.-J.; Shi, B.-B.; Lin, Q.; Yao, H.; Zhang, Y.-M.; Wei, T.-B. Supramol. Chem. 2016, 27, 552.

[62] Liu, R.-Y.; Gao, Y.; Zhang, Q.-B.; Yang, X.-D.; Lu, X.-W.; Ke, Z.-Y.; Zhou, W.-Q.; Qu, J.-Q. New J. Chem. 2014, 38, 2941.

[63] Zheng, X.-J.; Zhu, W.-C.; Liu, D.; Ai, H.; Huang, Y.; Lu, Z.-Y. ACS Appl. Mater. Interfaces 2014, 6, 7996.

[64] Ghosh, D.; Rhodes, S.; Hawkins, K.; Winder, D.; Atkinson, A.; Ming, W. H.; Padgett, C.; Orvis, J.; Aiken, K.; Landge, S. New J. Chem. 2015, 39, 295.

[65] Balamurugan, A; Lee, H. I. Sens. Actuators, B 2015, 216, 80. 
[66] Mahapatra, A. K.; Maiti, K.; Sahoo, P.; Nandi, P. K. J. Lumin. 2013, 143, 349.

[67] Liu, C.-X.; Xu,-J.; Yang, F.; Zhou,W.; Li, Z.-X.; Wei, L.-H.; Yu, M.-M. Sens. Actuators, B 2015, 212, 364.

[68] Ghosh, P.; Kumar, N.; Mukhopadhyay, S. K.; Banerjee, P. Sens. Actuators, B 2016, 224, 899.

[69] Kumar, D.; Thomas, K. R. J. RSC Adv. 2014, 4, 56466.

[70] Xu, S.-Y.; Sun, X.-L.; Ge, H.-B.; Arrowsmith, R. L.; Fossey, J. S.; Pascu, S. I.; Jiang, Y.-B.; James, T. D. Org. Biomol. Chem. 2015, $13,4143$.

[71] Iniya, M.; Jeyanthi, D.; Krishnaveni, K.; Chellappa, D. J. Lumin. 2015, 157, 383 .

[72] Kanagaraj, K.; Pitchumani, K. Chem. Asian J. 2014, 9, 146.

[73] Sen Gupta, A.; Paul, K.; Luxami, V. Spectrochim. Acta, Part A 2015, 138,67

[74] Wang, Y.; Zhao, Q.; Zang, L.-B.; Liang, C.-S.; Jiang, S.-M. Dyes Pigm. 2015, 123, 166.

[75] Ponnuvel, K.; Padmini,V. J. Lumin. 2016, 169, 289.

[76] Zou, C.-Y.; Qiao, Q.-L.; Zhao, M.; Mao, D.-Q.; Wang, D.-F.; Feng, L.; Cui, J.-N.; Xu, Z.-C. RSC Adv. 2014, 4, 43746.

[77] Li, Y.-H.; Duan, Y.; Zheng, J.; Li, J.-S.; Zhao, W.-J.; Yang, S.; Yang, R.-H. Anal. Chem. 2013, 85, 11456.

[78] Hu, R.; Feng, J.-A.; Hu, D.-H.; Wang, S.-Q.; Li, S.-Y.; Li, Y.; Yang, G.-Q. Angew. Chem., Int. Ed. 2010, 49, 4915.

[79] Calderon-Ortiz, L. K.; Tauscher, E.; Bastos, E. L.; Gorls, H.; Weiss, D.; Beckert, R. Eur. J. Org. Chem. 2012, 2535.

[80] Ke, B.-W.; Chen, W.-X.; Ni, N.-T.; Cheng, Y.-F.; Dai, C.-F.; Dinh, H.; Wang, B.-H. Chem. Commun. 2013, 49, 2494.

[81] Roy, A.; Kand, D.; Saha, T.; Talukdar, P. Chem. Commun. 2014, 50, 5510.

[82] Roy, A.; Kand, D.; Saha, T.; Talukdar, P. RSC Adv. 2014, 4, 33890.

[83] Roy, A.; Datar, A.; Kand, D.; Saha, T.; Talukdar, P. Org. Biomol. Chem. 2014, 12, 2143.

[84] Wu, Z.-S.; Tang, X.-J. Anal. Chem. 2015, 87, 8613.

[85] Turan, I. S.; Akkaya, E. U. Org. Lett. 2014, 16, 1680.

[86] Hou, P.; Chen, S.; Song, X.-Z. Luminescence 2014, 29, 423.

[87] Hou, P.; Chen, S.; Wang, H.-B.; Wang, J.-X.; Voitchovsky, K.; Song, X.-Z. Chem. Commun. 2014, 50, 320.

[88] Zhang, S.-L.; Fan, J.-L.; Zhang, S.-Z.; Wang, J.-Y.; Wang, X.-W.; Du, J.-J.; Peng, X.-J. Chem. Commun. 2014, 50, 14021.

[89] Peng, Y.; Dong, Y.-M.; Dong, M.; Wang, Y.-W. J. Org. Chem. 2012, $77,9072$.

[90] Wang, C.-Y.; Yang, S.; Yi, M.; Liu, C.-H.; Wang, Y.-J.; Li, J.-S.; Li, Y.-H.; Yang, R.-H. ACS Appl. Mater. Interfaces 2014, 6, 9768.

[91] Wu, X.-X.; Niu, Q.-F.; Li, T.-D. Sens. Actuators, B 2016, 222, 714.

[92] Huang, Y.-C.; Chen, C.-P.; Wu, P.-J.; Kuo, S.-Y.; Chan, Y.-H. J. Mater. Chem. B 2014, 2, 6188 .

[93] Cheng, X.-H.; Jia, H.-Z.; Feng, J.; Qin, J.-G.; Li, Z. Sens. Actuators, $B$ 2014, 199, 54

[94] Zheng, F.-Y.; Zeng, F.; Yu, C.-M.; Hou, X.-F.; Wu, S.-Z. Chem. Eur. J. 2013, 19, 936.

[95] Dhanunjayarao, K.; Mukundam, V.; Venkatasubbaiah, K. Sens. Actuators, $B$ 2016, 232, 175 .

[96] Yang, S.-J.; Liu, Y.; Feng, G.-Q. RSC Adv. 2013, 3, 20171.

[97] Li, L.; Ji, Y.-Z.; Tang, X.-J. Anal. Chem. 2014, 86, 10006.

[98] Yeh, J.-T.; Venkatesan, P.; Wu, S.-P. New J. Chem. 2014, 38, 6198.

[99] Kumari, N; Dey, N; Bhattacharya, S. Analyst 2014, 139, 2370.

[100] Imsick, B. G.; Acharya, J. R.; Nesterov, E. E. Chem. Commun. 2013, 49, 7043

[101] Ning, Y.-N.; Wang, B.; Mao, G.-L. Chem. Eng. 2014, (9), 66 (in Chinese).
(宁英男，王斌，毛国梁，化学工程师, 2014, (9), 66.)

[102] Xu, J.; Sun, S.-B.; Li, Q.; Yue, Y.; Li, Y.-D.; Shao, S.-J. Anal. Chim. Acta 2014, 849, 36.

[103] Wongsan, W.; Aeungmaitrepirom, W.; Chailapakul, O.; Ngeontae, W.; Tuntulani, T. Electrochim. Acta 2013, 111, 234.

[104] Mou, X.; Liu, S.-J.; Dai, C.-L.; Ma, T.-C.; Zhao, Q.; Ling, Q.-D.; Huang, W. Sci. Sin. Chim. 2010, 40, 979 (in Chinese).

(牟金鍂, 刘淑娟, 戴春雷, 马廷春, 赵强, 凌启淡, 黄维, 中国科 学: 化学, 2010, 40, 979.)

[105] Cheng, F.; Bonder, E.M.; Jakle, F. J. Am. Chem. Soc. 2013, 135, 17286.

[106] Liu, X.-L.; Mao, M.; Ren, M.-G.; Tong, Y.; Song, Q.-H. Sens. Actuators, B 2014, 200, 317 .

[107] Yuan, M.-S.; Wang, Q.; Wang, W.-J.; Wang, D.-E.; Wang, J.-R.; Wang, J.-Y. Analyst 2014, 139, 1541.

[108] Liu, S.-J.; Zhao, Q.; Xu, W.-J.; Huang, W. Prog. Chem. 2008, 20 1708 (in Chinese). (刘淑娟, 赵强, 许文娟, 黄维, 化学进展, 2008, 20, 1708.)

[109] Zhang, G.-J.; Wang, L.-M.; Cai, X.-F.; Zhang, L.; Yu, J.-J.; Wang, A.-L. Dyes Pigm. 2013, 98, 232.

[110] Wu, S.-Y.; Chen, Z.-J.; Zhang, K.-W.; Hong, G.; Zhao, G.-S.; Wang, L.-M. Tetrahedron Lett. 2016, 57, 1390.

[111] Wang, L.-Y.; Fang, G.-P.; Cao, D.-R. Sens. Actuators, B 2015, 221, 63.

[112] Misra, R.; Jadhav, T.; Dhokale, B.; Mobin, S. M. Dalton Trans. 2015, 44, 16052.

[113] Wang, L.-Y.; Li, L.-Q.; Cao, D.-R. Sens. Actuators, B 2016, 228, 347.

[114] Boxi, S. S.; Paria, S. Dalton Trans. 2015, 45, 811.

[115] Wang, H.; Hu, T.-Y.; Zhao, Z.-T.; Zhang, X.-Y.; Wang, Y.; Duan, X.-Q.; Liu, D.-W.; Jing, L.; Ma, Q. Talanta 2016, 149, 285.

[116] Dong, X.-L.; Zhou, Y.-H.; Song, Y.-M.; Qu, J.-P. J. Fluorine Chem. 2015, 178,61 .

[117] Bhalla, V.; Gupta, A.; Kumar, M. Talanta 2013, 105, 152.

[118] Liu, J.; Xie, Y.-Q.; Lin, Q.; Shi, B.-B.; Zhang, P.; Zhang, Y.-M.; Wei, T.-B. Sens. Actuators, B 2013, 186, 657.

[119] Kar, C.; Samanta, S.; Mukherjee, S.; Datta, B.K.; Ramesh, A.; Das, G. New J. Chem. 2014, 38, 2660.

[120] Maity, S. B.; Bharadwaj, P. K. Inorg. Chem. 2013, 52, 1161.

[121] Sen, B.; Mukherjee, M.; Banerjee, S.; Pal, S.; Chattopadhyay, P. Dalton Trans. 2015, 44, 8708.

[122] Razi, S. S.; Srivastava, P.; Ali, R.; Gupta, R. C.; Dwivedi, S. K.; Misra, A. Sens. Actuators, B 2015, 209, 162.

[123] Kaur, M.; Cho, M. J.; Choi, D. H. Dyes Pigm. 2014, 103, 154

[124] Hu, J.-Y.; Liu, R.; Cai, X.; Shu, M.-L.; Zhu, H.-J. Tetrahedron 2015, 71, 3838.

[125] Hinterholzinger, F. M.; Ruhle, B.; Wuttke, S.; Karaghiosoff, K.; Bein, T. Sci. Rep. 2013, 3, 2562.

[126] Bineci, M.; Baglan, M.; Atilgan, S. Sens. Actuators, B 2016, 222, 315 .

[127] Kim, H. Y.; Im, H. G.; Chang, S. K. Dyes Pigm. 2015, 112, 170.

[128] Wang, Z.-Y.; Li, J.-N.; Zhao, Y.-M. Green Chemistry General Course, China Textile Press, Beijing, 2007 (in Chinese). (汪朝阳, 李景宁, 赵耀明, 绿色化学通用教程, 中国纺织出版 社, 北京, 2007.)

[129] Wu, Y.-C.; Huo, J.-P.; Cao, L.; Ding, S.; Wang, L.-Y.; Cao, D.-R.; Wang, Z.-Y. Sens. Actuators 2016, 237, 865.

[130] Yang, K.; Wang, Z.-Y.; Fu, J.-H.; Tan, Y.-H. Prog. Chem. 2010, 22, 2126 (in Chinese).

(杨凯，汪朝阳，傅建花，谭越河，化学进展, 2010, 22, 2126.) 